COLLEGE OF AGRICULTURE

AGRICULTURAL EXPERIMENT STATION

Berkeley, California

\title{
Red Spiders and Mites of Citrus Trees
}

BY

H. J. QUAYLE

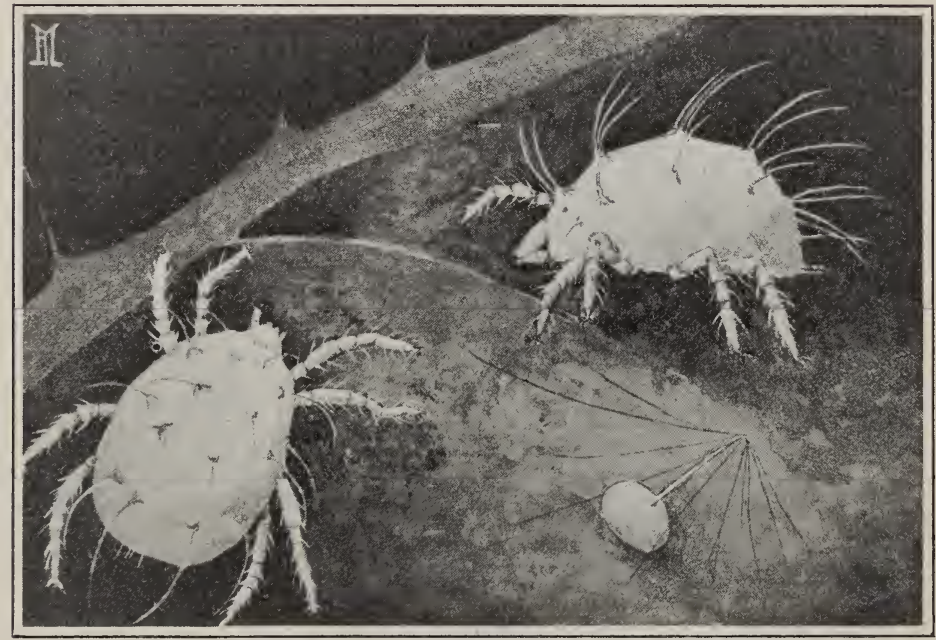

BULLETIN 234

BERKELEY, CAL., NOVEMBER, 1912

Friend Wm. Richardson, Superintendent of State Printing SACRAMENTO, CALIFORNIA 


\section{EXPERIMENT STATION STAFF.}

Thos. Forsyth Hunt, D.Agr., Director.

E. J. IVickson, M.A., Horticulturist.

E. W. Hilgard, Ph.D., LL.D. Chemist (Emeritus).

IV. A. SetChelL, Ph.D., Botanist.

Leroy Anderson, Ph.D., Dairy Industry.

M. E. JAFFA, M.S., Nutrition Expert.

R. H. Loughridge, Ph.D., Soil Chemist and Physicist (Emeritus).

C. W. WoodworTH, M.S., Entomologist.

RALPh E. Smith, B.S., Plant Pathologist and Superintendent of Southern California Pathological Laboratory and Experiment Station.

J. E. Cort, Ph.D., Citriculturist.

F. R. Marshall, B.S.A., Animal Industry.

H. J. WebBer, Ph.D., Director Citrus Experiment Station, Riverside.

A. V. Stubenrauch, M.S., Pomologist.

C. F. SHAw, B.S., Soil Technologist.

J. W. GregG, B.S., Floriculturist.

J. W. Gilmore, M.S.A., Agronomist.

G. W. SHAw, M.A., Ph.D., Experimental Agronomist and Agricultural Technologist, in charge of Cereal Stations.

B. A. EtcheverRy, B.S., Irrigation Expert.

F. T. BIoletTI, M.S., Viticulturist.

W. T. Clark, B.S., Assistant Horticulturist and Superintendent of University Extension in Agriculture.

John S. BuRd, B.S., Chemist, in charge of Fertilizer Control.

C. B. LipmaN, Ph.D., Soil Chemist and Bacteriologist.

George E. Colby, M.S.. Chemist (Fruits, Waters, and Insecticides), in charge of Chemical Laboratory.

H. J. QUAYLE, M.S., Assistant Entomologist.

H. M. HALl, Ph.D., Assistant Botanist.

C. M. Haring, D.V.M., Veterinarian and Bacteriologist.

E. B. BABCoCK, B.S., Agricultural Education.

W. B. HER MS, M.A., Assistant Entomologist.

W. B. Horne, B.S., Assistant Plant Pathologist.

L. M. Davis, B.S., Assistant Dairy Industry.

W. W. Bonns, M.S., Assistant Pomologist.

A. J. GAU MNITZ, M.S., Assistant Agronomist, University Farm, Davis.

T. F. Hunt, B.S., Assistant Plant Pathologist.

E. H. HagemanN, Assistant in Dairying, Davis.

J. I. Thоmpson, B.S., Assistant Animal Industry, Davis.

J. C. BRIDWELL, B.S., Assistant Entomologist.

L. Bonnet, I.A., Assistant Viticulturist.

F. C. H. Flossfeder, Assistant in Viticulture, University Farm, Davis.

P. L. HibBard. B.S., Assistant Fertilizer Control Laboratory.

C. H. McCharles, M.S., Assistant Agricultural Chemical Laboratory.

B. A. Madson, B.S.A., Assistant Experimental Agronomist.

Walter E. PACKARD, M.S., Field Assistant Imperial Valley Investigation, El Centro.

S. S. Rogers, B.S., Assistant Plant Pathologist, Plant Disease Laboratory, Whittier.

C. O. Sмrтн, M.S., Assistant Plant Pathologist, Plant Disease Laboratory, Whittier.

E. H. Sмгтн, M.S., Assistant Plant Pathologist.

C. L. Roadhouse, D.V.M., Assistant in Veterinary Science.

F. M. HAYES, D.V.M.. Assistant Veterinarian.

P. S. Burgess, M.S., Assistant Soil Chemist.

W. F. Gericke, B.S., Assistant Soil Chemist.

M. E. Stover, B.S., Assistant in Agricultural Chemical Laboratory.

W. H. VoLCK, Field Assistant in Entomology, Watsonville.

E. L. Morris, Field Assistant in Entomology, San José.

E. E. ThомAs, B.S., Assistant Chemist, Plant Disease Laboratory, Whittier.

A. B. SHAw, B.S., Assistant in Entomology.

G. P. GRAY, M.S., Chemist in Insecticides.

H. D. Young, B.S., Assistant in Agricultural Chemistry, Plant Disease Laboratory, Whittier.

A. R. Tylor, B.S., Assistant in Plant Pathology, Plant Disease Laboratory, Whittier.

IV. V. Cruess, B.S., Assistant in Zymology.

J. F. Mitchell, D.V.M., Assistant in Veterinary Laboratory.

M. R. Miller, B.S., Assistant Chemist in Insecticides.

F. H. WILson, B.S., Assistant in Soil Chemistry.

IV. M. Mertz, Assistant in Pomology, Riverside.

C. R. George, B.S., Assistant in Animal Industry.

AnNa M. Lute, A.B., Scientific Assistant, U. S. Dept. of Agriculture.

D. L. BunNELL, Secretary to Director. 


\section{CONTENTS.}

Introduction

Nature of Injury

Species Concerned _-_-_-_-_- 485

The Citrus Red Spider (T'ctranychus mytilaspidis Riley)___________ 487

Early Account _-_-_- 487

Nature of Injury

Distribution _- 487

Life History and Hahits____-_._- 488

The Egg -

Appearance -

Number - -

Proportion Hatching _-_-_-_-_- 489

Period of Incubation

The Young _-_- 489

Appearance and Emergence_._._._. 489

Process of Molting

The Adult _-_-_- 490

Description -

The Male -

Dispersion - -

Seasonal History _-

The Six-spotted Mite (Tetranychus sexmaculatus Riley) _-_-_-_-_-_-_-_ 492

Distribution in California_____-__-__- 492

Nature of Injury

Life History and Habits_______- 493

The Egg -

The Young Mite-_-_-_-_-_-_- 493

The Adult _- 493

Seasonal History - 494

The Silver or Rust Mite (Eriophyes oleivorus Ash.) _._-_-_-_-___-_-_ 494

Nature of Injury

Distribution -

Description, Life History, Habits___- 496

The Egg -_.

The Young Mite_-_-_- 497

The Adult _-

Tenuipalpus californicus Banks_-_-_-_-_-_-_-_-_-_-_-_-_-_-_-_ 497

T'etranychoides californicus Banks_-_-_-_-_-_-_- 498

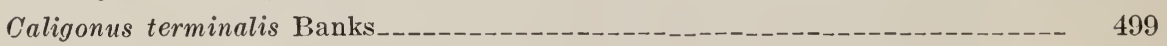

Tetranychus bimaculatus Harvey_-_-_-_-_-_-_-_-_-_-_-_-__-_-_-_- 500

Bryobia pratensis Garmen

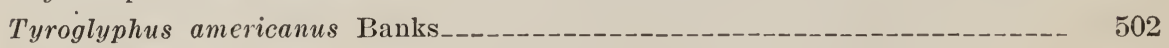

Gamasid sp. --_-_-_-_- 502

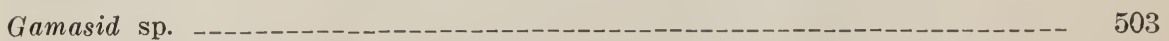

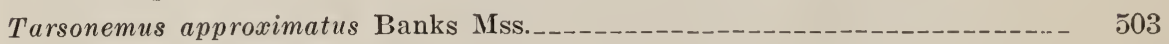

T'arsonemus assimilis Banks Mss.-_-_-_-_-_-_-_-_-_-_-_-_-_-_- 503

Eremøus modestus Banks_-_-_-_-_-_-_-_-_-_-_-_-_-_-_-_-_-_-_ 504

Key to the Species_-_-_- 505 
Natural Enemies

C'oncentzia hageni

The Egg

The Larva

Feeding of Larva

Pupation and Cocoon

The Pupa -

The Adult _.--

Oligota oviformis Csy.

Description, Life History, Habits_____- 509

The Egg -

The Larva _-

Manner of and Capacity for Feeding

The Adult _-

Stethorus picipes Csy.-_-_-_-_-_-_- 511

I)escription, Life History, Habits______- 511

The Egg _-

The Larva _-

The Pupa

The Adult _--

Scolothrips sexmaculatus Pergande___________- 513

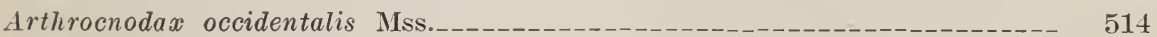

Parasite of Arthrocnodax__-

Thriphleps insidiosus Say

The Brown Lacewing

The Green Lacewing--_-_-

Other Enemies _-_-_-

The Control of Spiders and Mites on Citrus Trees_______-__-_- 519

Fumigation Not Effective

Lime Sulphur Spray_-_-_-_-_-

Dilutions _-

Cost - -

What the Spray Does

Dry Sulphur _-

How the Sulphur Acts

How Applied _-------------

When the Application Should be Made---

Materials _-

Dry Sulphuring the Fruit Pickers__-__-

The Dry versus the Liquid Spray

Distillate or Kerosene Emulsion

Other Sprays _.

Summary _- 


\title{
RED SPIDERS AND MITES OF CITRUS TREES.
}

\author{
By H. J. QuaYle.
}

\section{INTRODUCTION.}

Next to the scale insects, red spiders and mites are the most important pests of citrus trees in California. On account of their small size, and because the foliage and fruit of the tree are not conspicuously marred cither by their presence or by the covering of sooty mold fungus, as is the case with some of the scale insects, the actual injury done by red spiders and mites is not always appreciated. Their distribution is very general over the citrus sections, and they may be found in some numbers at most any season of the year. So long as they do not become numerous the injury they do is not important and in such cases it is not good economy to apply treatment. Because of their more or less continual presence in scattering numbers some growers take red spiders as a matter of course, and fail to recognize their importance when they become abundant and do damage, or come to a realization of their injurious nature after most of the damage has been done and the spiders themselves begin to disappear, as they often do. While, therefore, the presence of spiders in scattering numbers should be the cause of no particular concern, the presence of excessive numbers of spiders should be the cause of enough concern for the grower to start immediately to apply control measures. Dropping of the leaves and fruit is the ultimate result of red spider injury. But the cause should be checked long before this extreme effect is evident.

Nature of Injury. The first indication of red spider work is to be seen in the pale spots, scattered about over the leaf surface, which represent their feeding places. In the case of the commonest species these areas are very small and represent often, probably, but a single insertion of their mouth parts. In the next most important species on citrus trees, the feeding is restricted very largely to definite areas, and these become yellowish in color and conspicuous even from a distance. As the feeding areas become numerous most of the functional green-matter in the leaf is absorbed, and such a leaf assumes a grayish or yellowish color and is of little use to the tree. Leaves thus affected fall prematurely, and sometimes there is a heavy denudation as a result of red spider injury.

As a rule red spiders are most numerous in the spring, April, May, and June. Anything that tends to diminish the vigor of the tree at this time, as an impairment or dropping of the leaves, must have its effect on the setting or maintenance of the crop. Aside from this, however, the spiders attack the fruit directly. The pale silvery color of 
green fruit is characteristic of red spider or mite injury. Such fruit either falls from the tree or never attains its usual color. While spring is the most favorable season for spiders, they often become abundant also in the fall, and less often at other seasons. Some of the worst effects of red spider injury noted by the writer occurred in the fall and early winter of 1911 . At this time as the fruit is maturing the spiders give it a pale lusterless yellow color, instead of the normal bright orange. This change in the ripening fruit, in the case of Valencias, may be due also to the spring crop of spiders.

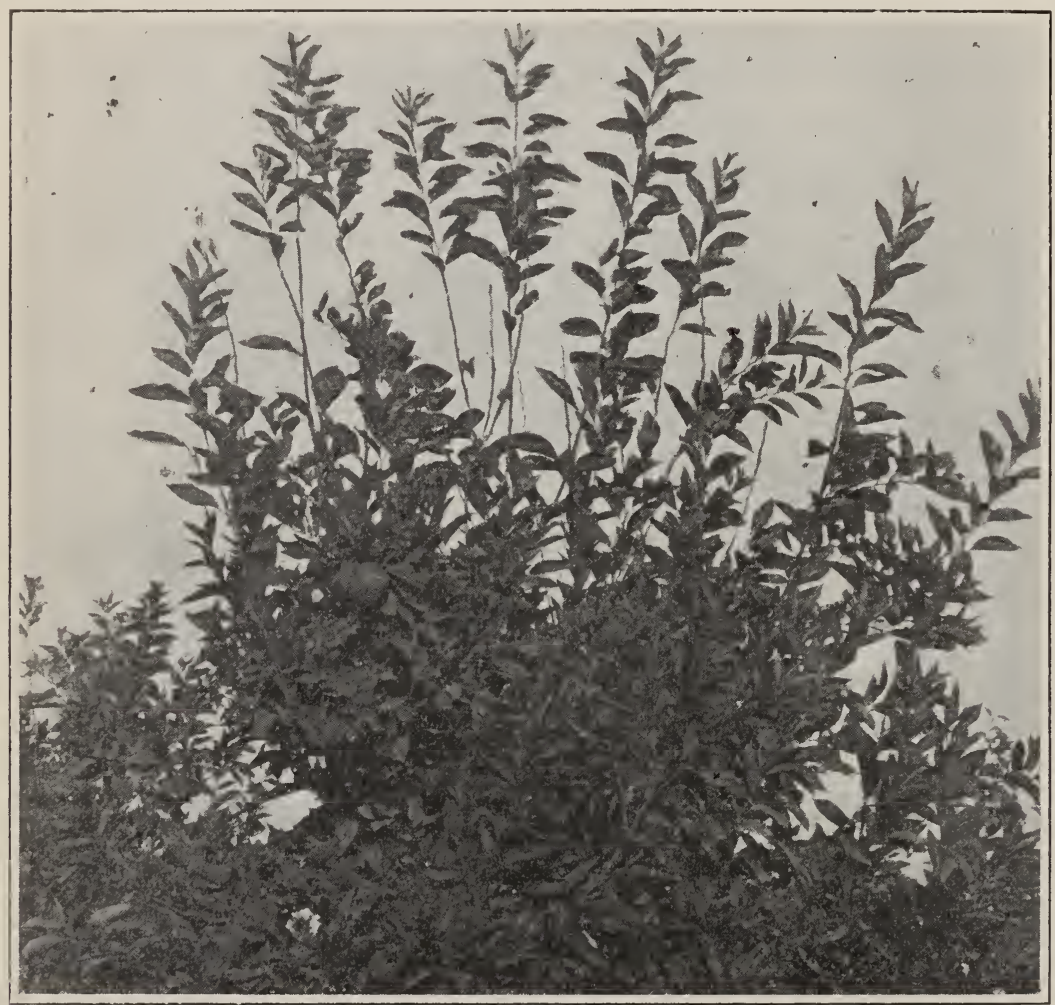

FIG. 1.-Top of a citrus tree partially defoliated by work of Red.Spiders.

Another phase of injury which has often been brought to our attention is the possibility of spiders and mites being responsible for the distribution of fungus spores and thus indirectly disfiguring the fruit or starting infection on the more tender twigs. While such effects are still obscure, there is every likelihood that red spiders, by their moving about from one place to another and making abrasions in the epidermis, might be the means of spreading fungous or bacterial troubles. A reddish stain sometimes develops on the fruit even long after the attacks of the spiders and this is often attributed to their work. Still another 
effect of such pests, which is indicated very strongly by our general observations, is that they appear sometimes to be the primary cause of the dying back of the tips of the twigs. Where twigs are defoliated by their work, they may be killed or greatly weakened and such twigs are then likely to be attacked by other troubles such as the "wither-tip" fungus and die-back. It occasionally happens that red spiders give trouble in packing-houses by continuing to breed on the fruit, particularly the lemon, during curing or storage. It is possible, also, that mites may aid in the spread of decay infections while the fruit is in transit. After lemons had been kept in a tightly covered glass dish in the laboratory for six or seven months we have taken numerous mites representing three different species.

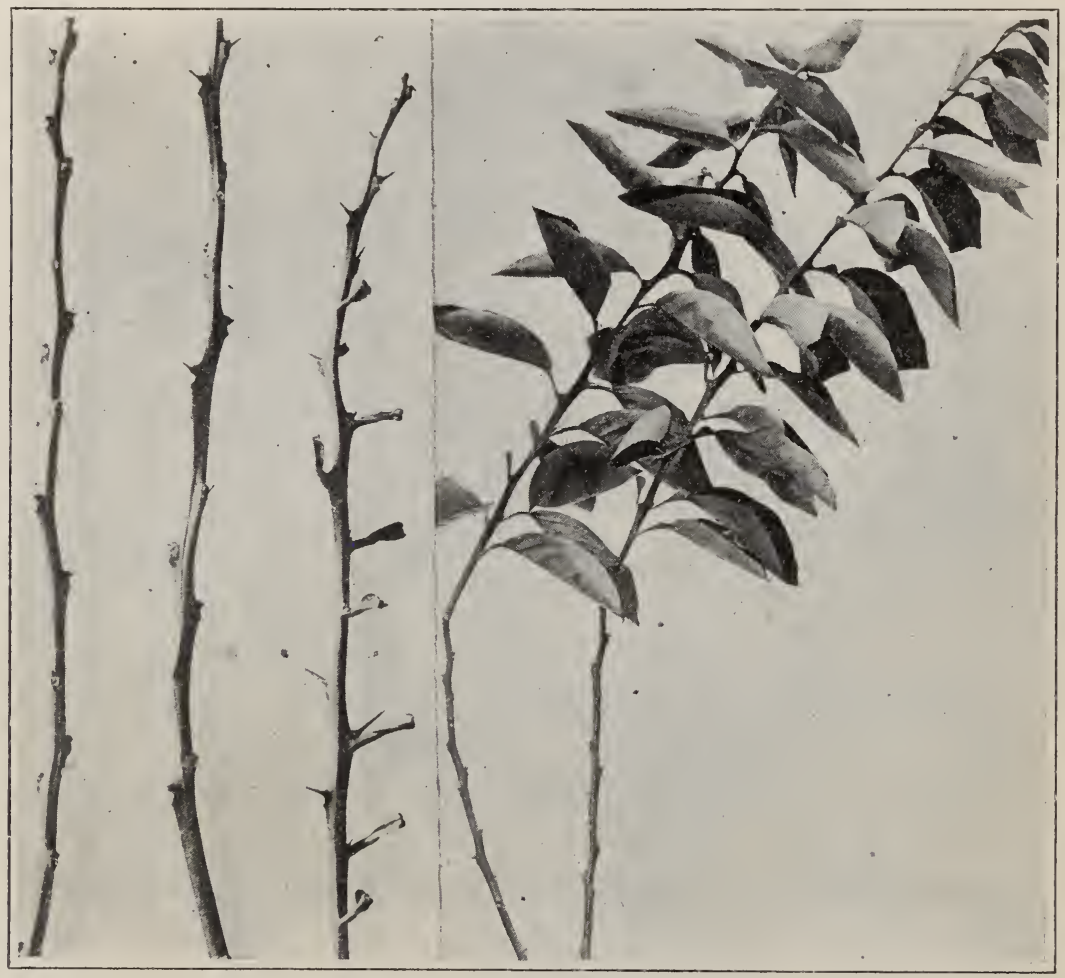

Fig. 2.-Orange twigs defoliated by Red Spiders.

Species Concerned.-Red spiders and mites belong to the order Acarina, of the class Arachnida, and are, therefore, not insects which are included in the class Insecta. Structurally, spiders and mites differ from insects in having, usually, four pairs of legs instead of but three as insects do, and, further, in that the body is not divided into three distinct regions, head, thorax and abdomen, as is characteristic of adult insects. Practically, in so far as it relates to their control on citrus 
trees, they differ from most insects because they are not killed by the ordinary fumigation dosages.

There have been recognized three more or less well known species of

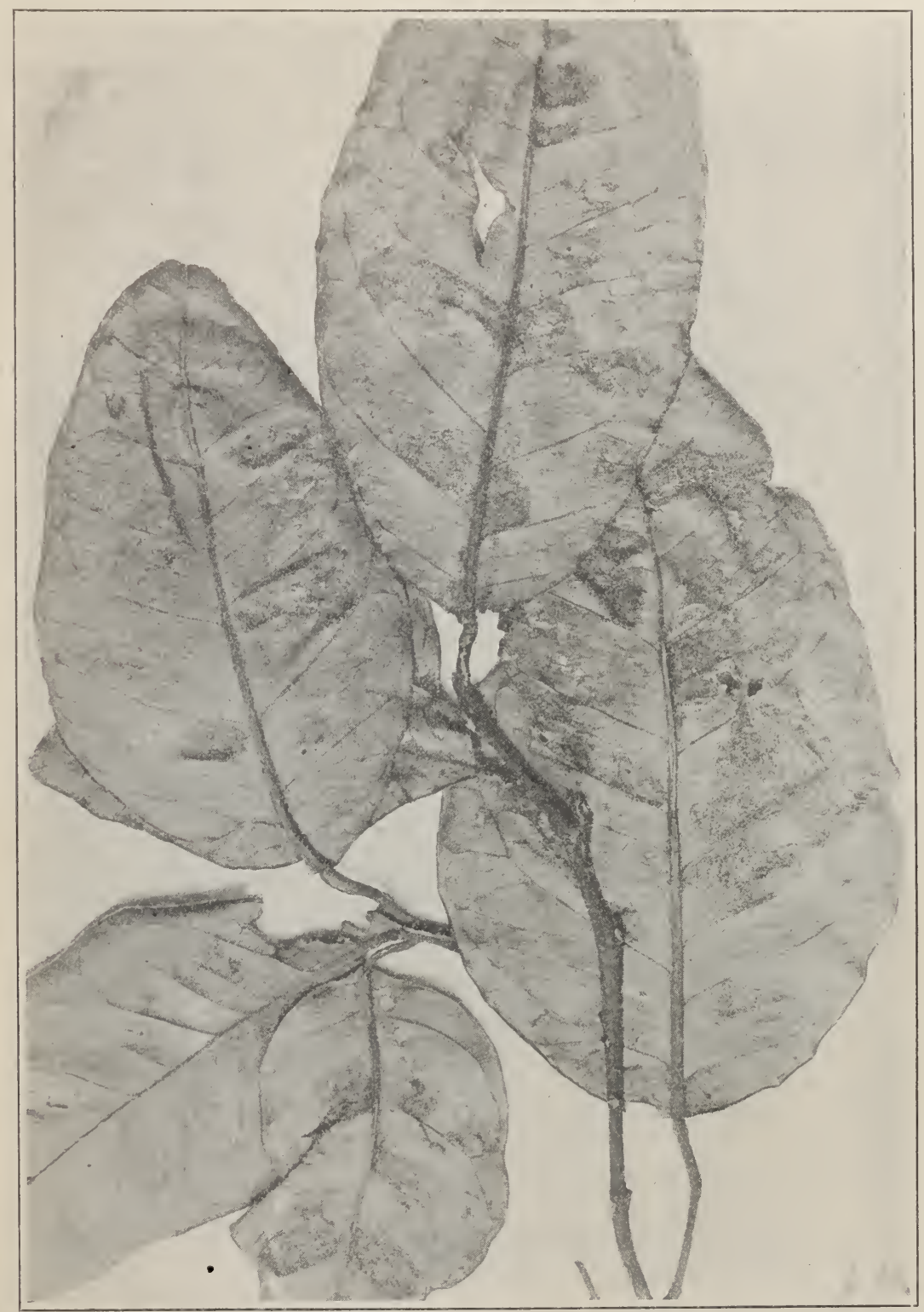

FIG. 3.-Orange leaves showing work of Six-spotted Mite.

spiders and mites that attack citrus trees in California. These are the citrus red spider (Tetranychus mytilaspidis Riley), the six-spotted mite (Tetranychus sexmaculatus Riley) and the citrus rust mite or silver 
mite (Eriophyes oleivorus Ash.). The present studies have brought out several other species that are found on citrus trees, but none of these rank in importance with the three mentioned. In the following pages the species are discussed separately in the order of their importance, and following this the different species of natural enemies receive consideration. Practical growers who are interested chiefly in how to control spiders and mites will find a discussion of such measures on page 519 and a summary account of this bulletin on page 530 .

Mr. J. D. Neüls, who has assisted the writer during the present year has made many of the observations herein recorded.

\section{THE CITRUS RED SPIDER.}

(Tetranychus mytilaspidis Riley.)

Early Account.-This species was first described from specimens taken from the orange in Florida in 1885.* It was introduced into California from Florida on nursery stock in about 1890. It doesn't appear to be as injurious in Florida as sexmaculatus, while in California it is much more injurious than the latter species. Mytilaspidis has been a pest in the State since about 1895. Early in 1900 a demand was made from the citrus growers for a study of the spider because of its injurious nature, and also because of its supposed relation to the spotting of the fruit due to the old distillate spray, and a bulletin, now out of print, was issued by Professor Woodworth in 1902.

Nature of Injury.-This species causes the more characteristic mite injury as represented at first by pale colored specks over the surface of the leaf and fruit, these gradually increasing in numbers until they become numerous enough to produce a general pale gray or silvery effect over the whole of the leaf and fruit. The leaves are the first to show this effect and later the fruit. The tender twigs are also attacked and when the spiders are abundant numerous eggs and cast skins will be found on them. This is the species that has given the most trouble in the packing-house because it so readily attacks the fruit. It is distinctly the most injurious of all the species found on citrus trees.

Distribution.-The citrus red spider is the most widely distributed of all the species and is the one that most control work is directed against. It occurs very commonly in San Diego County, as well as elsewhere, but there the six-spotted mite is sometimes more important. Mytilaspidis has been presumed to be limited to the citrus fruits, and, consequently occuring in California, Florida and elsewhere where citrus fruits are grown. Mr. H. E. Ewing states, however, that he finds the species a pest on plum, prune and other deciduous trees in Oregon, and we have taken it on apple and some of the other deciduous trees growing among the citrus trees in southern California.

*Hubbard, H. G. Insects Affecting the Orange. Div. Ent., U. S. D. A., 1885. 
It has not been reported as injurious thus far from the citrus section of the San Joaquin or Sacramento valleys, but is generally distributed in the citrus sections south of the Tehachapi. In the citrus section this species is restricted almost entirely as a pest to citrus trees. Reports of the spiders overrunning everything as ornamentals, vegetables and cover crops have been frequent, but in every case they have not proved to be T. mytilaspidis. On ornamentals particularly violets, and such vegetables as beans, the species is generally $T$. bimaculatus. On almond and apricot trees, and on such cover crops as vetch, the species is usually Bryobia pratensis. Almond trees surrounded on all sides and immediately adjoining citrus trees are usually infested with the latter species.

Mytilaspidis is a species well adapted to the warmer and dryer sections, althought it is not limited to such conditions. The fact that it is more injurious here than in Florida and its distribution in this State is general in the interior sections appears to indicate this; while sexmaculatus is the more injurious of the two in Florida, and its distribution here is limited to the Coast counties making it a species better adapted to more humid conditions.

\section{LIFE HISTORY AND HABITS.}

THE EGG.

Appearance.-The egg of mytilaspidis, see outside cover, differs from that of all other species found on citrus trees by the presence of guy threads radiating from the top of a vertical stalk. It sometimes happens that the eggs of some of the other species will have a more or less indefinite stalk, but they never have the supporting guy threads, or even a regular or definite stalk. The egg itself is spherical in shape but slightly flattened at the poles. When first laid it is uniformly bright red in color, but later this color pigment gathers in particular areas, usually at one side and finally the eyes and outline of the developing spider can be made out. The stalk arises vertically and measures about twice the diameter of the egg. From the top of the stalk there radiate, in a somewhat regular manner, from twelve to fourteen guy threads which extend down to the leaf, forming a tent-like arrangement over the egg. As soon as the egg is deposited the abdomen is raised to form the stalk, and afterward move from the top of the stalk to the leaf several times, thus forming the supporting guys. The purpose of these radiating threads may be to hold the egg in place, though this could be accomplished by the secretion of an adhesive substance which is the lisual way. They may be for protective purposes, since the egg is enclosed in a canopy of these threads which may deter some of the natural enemies from reaching them. It must be said, however, that the enemies discussed farther along were not observed to be limited by 
this frail stockade. In the case of sexmaculatus the eggs are protected to a considerable extent by being deposited beneath, or entangled in, a more dense network of web.

Number.-The number of eggs produced by this species will average about thirty, or at least this represents what we have been able to obtain under conditions as nearly natural as possible. The average number deposited per day for the producing period will be between two and three. Some days as many as six or seven may be deposited but other days but one or two and occasionally none. As an illustration, daily records made on the deposition of 285 eggs show that they were deposited in 113 days by 13 spiders. This is an average of two or three a day and an average of $22 \mathrm{eggs}$ for each spider. Some of these, however, were not counted for the full ovipositing period.

Proportion Hatching.-Ordinarily a large proportion of the eggs hatch if they are not attacked by predaceous enemies. Thrips, Coniopteryx, Staphylinid beetle, syrphus fly and lacewing larvæ all may attack red spider eggs. Sometimes, however, the reason for not hatching is unknown and occasionally the percentage thus failing to hatch will reach as high as 50 per cent.

Period of Incubation.-The time required for the eggs to hatch varies from eight to ten days in summer to three weeks or even longer in winter. During the season when they are most abundant about ten days will be the average hatching period.

\section{THE YOUNG.}

Appearance and Emergence.-The young spider is very much like the adult excepting that it is smaller in size and has but three pairs of legs. The fourth pair is acquired upon the first molt. The egg splits in an even line around the equatorial zone and through the efforts of the spider the parts are separated on one side as though hinged. The fore legs and front part of the body are first freed, and often when in this stage of emergence they apparently insert their mouth parts and begin to feed. When they finally crawl out, the two halves of the eggshell which have been held apart by the emerging spider spring back into place again. It is now perfectly transparent, but otherwise appears as a normal egg. Sometimes the parts of the egg covering may remain separated, and in such cases, that hatching has occurred is very evident. Where the egg is simply transparent it may be due to the attacks of one of several enemies, and to determine whether the egg has hatched or not it is necessary to examine closely enough to make out the crack in the shell.

Feeding begins just as soon as the young emerge. On the second or third day the first molt occurs. After two or three days more the second molt takes place and a similar period elapses for the third and last molt. In a majority of cases three days represent the period between hatching and the first molt, while between the other molts two days is very frequently the period. This is based upon records of upwards of a hun- 
dred spiders. It not infrequently happens that the male completes its development in one day less than the female, and males have often been seen to assist the females in freeing themselves from their last cast skin.

Process of Molting.-Preceding the actual discarding of the old skin the spider is quiet for some time and becomes much paler in color, particularly the appendages. With the light colored species the old skin can be distinguished by its transparency just preceding the molt. The skin is split transversely around the middle of the body between the second and third pairs of legs. By raising the center of the body upward the parts of the old skin are separated on the dorsal surface. The front part of the body is then pulled out of its old covering, and the front legs being free, it pulls itself or simply walks out of the posterior pocket. Sometimes the latter adheres to the spider until after it has traveled some little distance so the two halves of the cast skin are sepaiated. In other cases the break does not occur on the ventral surface and the parts are kept together.

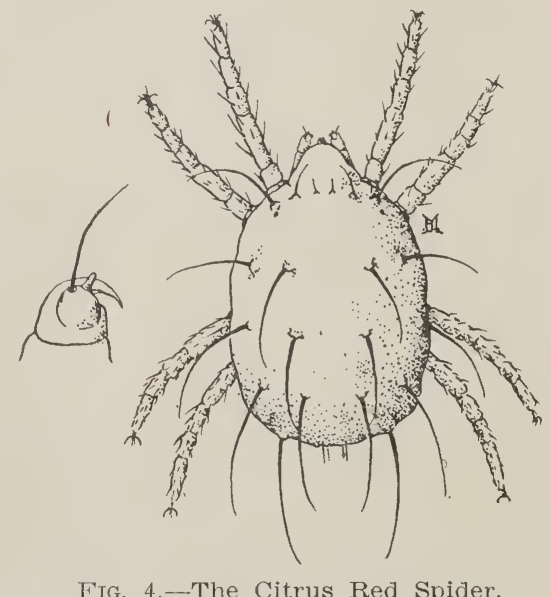

Tetranychus mptilaspidis Riley.

THE ADULT.

Description.-The citrus red spider, T. mytilaspidis, is not difficult to distinguish from all the others found on etrrus trees. It is distinctly red in color, though different shades of red may be represented in different individuals. Most commonly it is of a dark velvety color and not smooth and shiny as are some of the other associated species. In size it is larger than most others found with it, the body being robust and rounded above. One of the definite characters that serves to distinguish this species from other members of the same genus is that the bristles covering the body arise from prominent tubercles. The bristles are large and white in color. Only one other species of the genus Tetranychus has the tubercles and this is not found, thus far, on citrus trees. Since eggs are usually found with the spiders, an examination of these eggs for the stalk and radiating guy threads will serve to distinguish the 
species. For the more technical characters that separate the species see table on page 505 .

The Male.-The male of this species, as is true with most others, is considerably smaller than the female. Instead of the body being robust and oval, as is the female, it becomes more narrowed and pointed posteriorly. The body of the male is capable of considerable telescopic action which is evident in pairing when it is greatly extended and curved upward, the female being above. Eggs will be deposited in the absence of fertilization and these normally hatch into individuals of the male sex only. Out of 81 eggs laid by unfertilized females 65 hatched and all were males. The production of males only from unfertilized eggs appears to be the case also with $T$. bimaculatus. Out of 34 unfertilized eggs laid by this species 27 hatched and all were males.

Dispersion.-Red spiders of this species are very active and may travel about very generally over the tree, but usually they remain throughout their life on the same or adjoining twigs. The fact that they are found on the ground is not an indication that they live there or may develop there. Those that occur on the ground have fallen there, either by themselves, or upon a leaf, or have crawled down the tree trunk. They can also make considerable headway on the ground and thus reach other near-by trees by their own powers/ of locomotion. Several experiments to determine the rate of travel over orchard soil indicate that they may travel on an average at the rate of from 4 inches to 10 inches in an hour. From two to four days is the maximum period they will live without food. They are also very quickly killed on the ground with a temperature of 110 degrees or higher. A grove that received very efficient treatment in the fall of 1911 was entirely free from spiders, even well into the season of 1912, with the exception of the first few outside rows. The adjoining groves had many spiders, and it seemed very evident that those on the margins of the treated grove became infested from these, and through the movement of the spiders themselves. In addition, birds and insects, as well as man in his general cultural operations, may be responsible for more or less dispersion of the spiders.

Seasonal History. - The citrus red spider appears in greatest numbers during May and June. With the higher temperatures of midsummer their numbers may decrease considerably or almost entirely disappear. Commonly they do not again appear in large numbers until the following spring. But exceptions occur to this, and not infrequently they become abundant in the late fall or early winter.

It is not possible to state definitely the number of generations that occur in a season. Spiders will be found in all stages at nearly all seasons of the year. During the warmer season, from May to October, the period from hatching to maturity will be just three weeks. During the colder, wet season it will be extended to five weeks, most of this additional time being required for the eggs to hatch. On this basis there 
may be from 12 to 15 generations during the year. The entire life cycle from hatching to the death of the adult occupies from thirty-five to forty days, divided as follows: egg ten days, first stage three days, second stage three days, third stage three days; adult eighteen days. Mating occurs immediately after the last molt and egg laying begins from two to three days later.

The natural enemies of this species will be found discussed on page 505 and control measures on page 519 .

\section{THE SIX-SPOTTED MITE.}

\section{(Tetranychus sexmaculatus Riley.)}

This mite first came into prominence as a pest on orange trees in Florida in 1886. Brief mention is made of it by Hubbard in 1885 but no adequate description appeared until it was described by Riley in 1890.* It was first recorded on the wild orange in Florida and later became a pest on other species of citrus. In the report of the Secretary of Agriculture for 1889, Riley has also given a discussion of its life history and economic importance. In this account one of the common rames then known to be applied was "California spider," and from this it would appear that it was known in this State at least as early as 1889. That it was introduced into this State on nursery stock from Florida in the late eighties appears to be fairly well established.
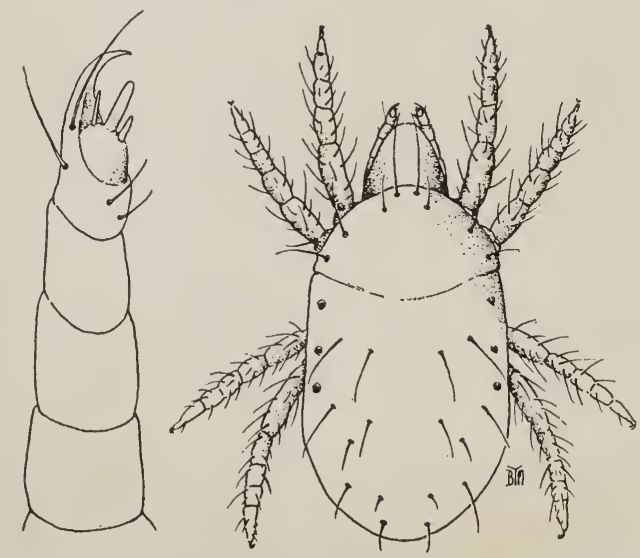

FIG. 5.-The Six-spotted Mite, Tetranychus sexinaculatus Riley. Palpus on left.

Distribution in California.-The six-spotted mite is most important as a pest in San Diego County. It is widely distributed throughout that section. It also occurs in Los Angeles, Orange, and Santa Barbara counties, but very scattering, only a few trees here and there or an occasional grove will be found infested. We have not taken it in Riverside and San Bernardino counties and the horticultural commissioners of those counties, Mr. Cundiff and Mr. Pease, state that it does not occur 
there to their knowledge. Neither has it been taken, thus far, from Ventura County. From its more general distribution along the coast it appears to be a mite better adapted to regions of more moisture.

Nature of Injury. - The work of the six-spotted mite is very characteristic and is easily distinguished from that of all the other species. This mite is very definitely confined to particular areas. These are on the under side of the leaf and usually along the midrib or larger veins but sometimes close to the margin. There is a distinct depression formed where the colony has its headquarters. This depression is of a pale yellowish color and is covered with a web which protects the spiders beneath, and which also serves as a support for the eggs which will be seen scattered about entangled in the silk. Beneath this web the leaf surface is a yellowish color, due to their feeding, and there are present also the molted skins and small black particles of excrement. On the upper surface of the leaf this same area is represented by a raised portion or swelling which is distinctly yellow, or yellowish white in color, and has a smooth shiny surface. In cases of severe injury by these mites these areas may make up the greater portion of the leaf, and such leaves, particularly if they are growing leaves, become very badly distorted and misshapen.

\section{LIFE HISTORY AND HABITS.}

The Egg.-The egg of this species is white or yellowish white in color and perfectly round. The eggs will be found in the areas where the mites feed and are usually entangled in the web which serves as a protection, or they will be found on the leaf surface beneath this web. From twenty-five to forty eggs will be deposited during a period of ten to twenty days. They require five to eight days for hatching in June. This will be extended to three weeks during the winter months.

The Young Mite.-A young mite that hatched from the egg on July 10th molted on the 12th, two days later. The fourth pair of legs, as in the other species, appears after this molt. The second molt occurred on the 14th and the third and last molt on the 16th. This mite was a male. Another hatched on the same day, molted on the 12th, 14th and 17th. This one was a female and required one day longer. It often happens that the male will complete its development in one day less than the female. The two specific cases given represent the time required for the development of the mite during June and July, as determined from a number of rearing records. It thus requires from six to nine days for the development of this species, and allowing two or three days more before egg-laying begins the total period from the egg to maturity will be from eight to twelve days. The manner of molting and other details in development are essentially the same as in the previous species, which has already been discussed.

The Adult.-The adult of this species is generally smaller than mytilasphidis, and it is never red in color. The color, however, varies greatly and in some a considerablè amount of the dark pigment will be 
seen and some indication of this pigment coalesced into six areas or spots, hence the name sexmaculatus or six-spotted mite; but in others no trace of pigment is present and the mite will appear of a uniform light pink or pale greenish yellow color. It is clothed with many hairs but there are not so long as in mytilaspidis nor do they arise from tubercles. This six-spotted mite is thus easily distinguished from the citrus red spider, but it is not so easily distinguished from Tetranychus bimaculatus, or the common red spider. Indeed, structurally they are very similar, the difference is supposed to be in the number of fingers on the thumb of the palpi and this seems to be variable. But the bimaculatus that occurs on violets, beans, and many other plants in the citrus belt is not only different in habits, but the mite itself is very diferent as regards coloring, though occasionally the difference is not so distinctly marked. This question of identity is discussed further under bimaculatus on page 500 .

Eggs are deposited at the rate of from two to five a day for a period of ten or fifteen days. While the adult, as well as the young, may frequently be found away from their web-protected home, feeding must be largely restricted to the areas protected by the web since no other parts of the leaf show such serious injury. In a bad infestation of course these areas cover nearly the entire leaf.

Seasonal History. - This species becomes most abundant usually in the spring or early summer. Very severe defoliation from this species has been seen in May and June, but not infrequently sulphur is applied in San Diego to control them in August and September. Sometimes they also become abundant during a warm, dry period in midwinter. Since the eggs hatch in five to eight days, eight to twelve days are required for the development of the young, and the adult lives ten to fifteen days, the complete life cycle requires from three to four weeks. Seasons when they are not noticeable or abundant doesn't mean that they have disappeared entirely, but that breeding is occurring so slowly as to make their effect on the tree inconspicuous. One generation follows another more or less irregularly throughout the season, and there are a total of from twelve to fifteen. The control of this species is given beginning on page 519 .

\section{THE SILVER OR RUST MITE.}

\section{(Eriophyes oleivorus Ash.)}

The silver or russet mite was introduced into this State from Florida in 1889. It is called the rust mite in Florida because of the brown or russet effect it produces on the oranges, the principal variety of fruit grown there. In this State it is known as the silver mite because of the white or silvery effect it produces on the lemon, the principal variety of citrus grown in the section of the State where it occurs. This mite was originally described from Florida, and is known to attack only the different varieties of citrus. It is probably a native of Florida where the wild orange served as its original food plant. 
This species belong's to a very different group of mites than the ones thus far discussed. It belongs to the family Eriophyida which include small four-legged mites of a vermiform or worm-like shape, and so small as to be scarcely visible to the naked eye. In this family are included the leaf-blister mite of the apple and pear; another causes the erinose of the grape, and another a similar affection, characterized by fuzzy brown spots, on the leaves of the English walnut.

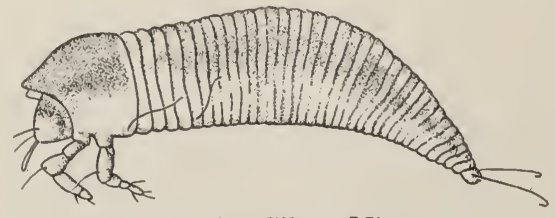

FIG. 6.-Silver Mite.

Nature of Injury.-The silver mite has mouth parts similar to the red spider, and the manner of injury is much the same. But the ultimate effect of silver mite injury is easily distinguished from red spider or other mite injury. This may be partly because it becomes more numerous and the injury is more pronounced, for a mild case of silver mite

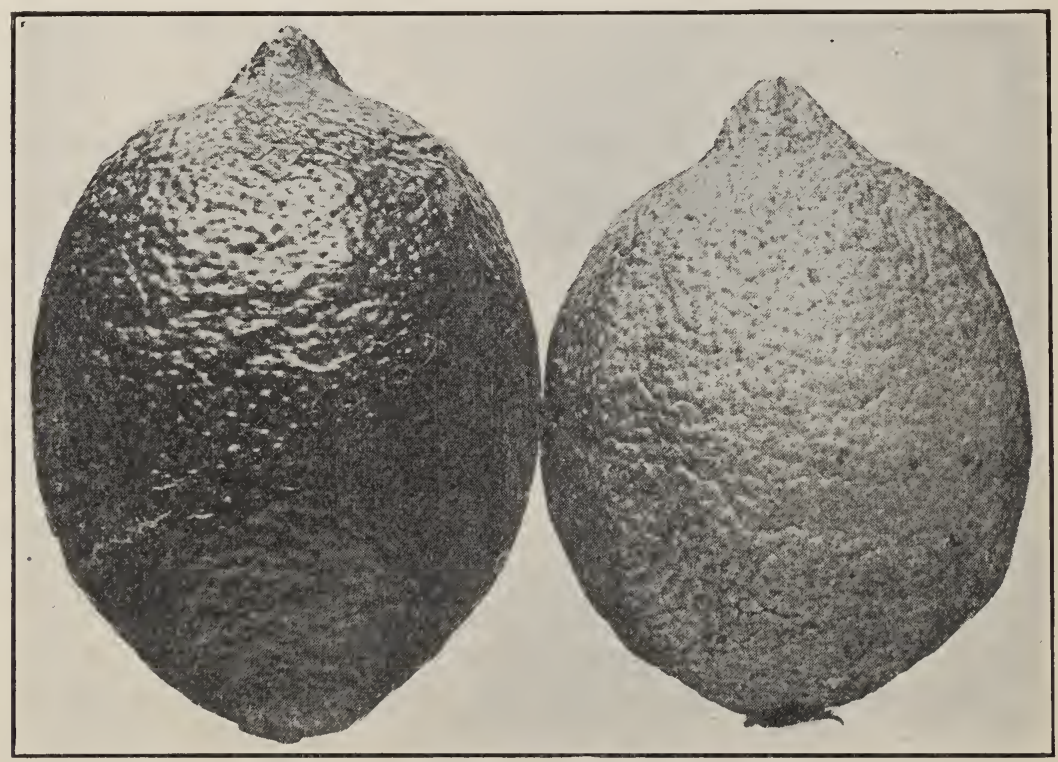

FIG. 7.-Lemon on right showing work of Silver Mite.

injury may be difficult to distinguish from the citrus red spider injury. A lemon badly infested with silver mite becomes distinctly white or silvery in color and much more pronounced than in the severest attack of mytilaspidis. Silver mite injury is much more restricted to the fruit, while the others really produce injury to the leaves first. It is also often confined to a more or less definite area on the fruit, as the upper side, while red spider injury is more uniform. The rind of lemons that have 
been injured by silver mite becomes very hard and is covered with a network of cracks.

The attacks of this mite affect the lemon somewhat differently from the orange. The ripening orange becomes very distinctly browned or russeted, while on the lemon the characteristic injury is the white or silvery appearance. But this difference is not so great as it apparently seems. On both the orange and lemon, while they are small or green, the effect is similar, though the silvered appearance is more marked in the case of the lemon. Since the lemon is picked when it attains a certain size, and is, hence, usually green, the brown color has not yet developed, while the orange is allowed to ripen on the tree and the brown or russet effect becomes very evident. In case of the tree-ripe lemons the browned effect is apparent, but never so marked as with the orange. This silvered, and later, russet, effect is due to the mites taking up the oils and green matter from near the surface, causing the rind to dry and crack. While the most noticeable injury by this mite occurs on the fruit, it also occurs on and does injury to the leaves. The leaves lose their green, glossy appearance and become pale colored or silvery and sometimes curled.

Formerly a special demand was created for the russet orange of Florida, which was supposed to be sweeter and also possessed better keeping qualities. The injury that occurred on the surface, in the case of nearly mature fruit at any rate, apparently does not affect the quality of the interior. The market demands, however, a good appearing fruit, as well as a good tasting fruit, and the russet orange is not so popular as formerly. Moreover, such artificial injury to the fruit must be shared to some extent, at least, by the foliage, and consequently the vigor of the tree is more or less impaired. It is of special importance, however, that the rind of the lemon appears bright and attractive, and thus "silvered" or "russeted" lemons have found no sale whatever. When the pest first appeared in California the lemons were discarded as culls, but later they were utilized by the citric acid factory. There is no longer any excuse whatever for suffering any serious loss through the silver mite, though the loss will occur unless treatment is applied when the mite appears.

Distribution.-In California the silver mite is restricted to a limited section in San Diego County. It was introduced here directly from Florida, and never seems to have become established elsewhere. There are other citrus sections where the climate is very similar, and there is every reason to suppose that it would thrive elsewhere, particularly in the coast sections. This is another species that seems to do best in sections of more or less moisture. In Florida it is generally distributed throughout most of the citrus sections.

\section{DESCRIPTIONS-LIFE HISTORY-HABITS.}

The Egg.-The egg of this mite is white or transparent in color, with some showing a slight tinge of yellow. They are circular in shape and very minute, being scarcely visible without a magnifier. Four or five 
days are required for hatching during the summer months, and as long as ten days to two weeks during the colder and wet weather of winter. Our records on the number of eggs are fragmentary. The maximum number from one female is fifteen, but it is possible that this may be exceeded. However, from such records as were made, and from general observations, fifteen or twenty eggs seem to be an average number.

The Young Mite.-The first-hatched mite is elongated, about three times as long as broad and of a light yellow color. It is thus much more worm-like than any of the other mites found on citrus trees. The cast skins, which may be seen on the foliage of fruit after the mites themselves have disappeared, are very minute, tapering, or cornucopia-like objects.

The Adult.-Even the full grown mite is very minute, not measuring more than $.15 \mathrm{~mm}$ in length, which is equal to about $3 / 500$ of an inch, The body consists of two parts, the head fused with the thorax and known as the cephalothorax, as in other mites, and a very much longer, tapering abdomen, which is made up of a number of rings. The head is pointed and bent downwards. The rostrum contains two slender stylets, the mandibles, which are used for piercing the plant. On each side of the rostrum is a three-pointed maxillary palpus, and these serve as antennæ. The abdomen is cylindrical and transversely striated, giving it the appearance of being made up of a number of segments or rings.

On account of the short time required to reach maturity, eight to ten days, these mites may become very abundant. They have very limited powers of locomotion, and, hence, but a portion of a tree or a few trees here and there will be found infested, rather than a general distribution over the whole grove. Sometimes the evidence of injury is limited to but a few of the fruit.

For control measures see page 519 .

\section{Tenuipalpus californicus Banks.}

This is a small species that is somethimes found on citrus trees in considerable numbers but the actual evidence of injury is not often apparent. It is a red species of small size that is characterized by its flatness. They are usually motionless and lie very flat upon the leaf or fruit and look not unlike minute scales. This is the only species of the genus Tenuipalpus recorded from the United States. What appears to be another species has been found on the Boston ivy. This one was so abundant on ivy growing on the courthouse at Santa Barbara as to seriously injure it. The cast skins almost completely covered the upper surface of the leaves in many cases.

Color, red. Body widest at cephalothorax and then suddenly narrowing, making the abdomen appear more or less cylindrical. The margin of the cephalothorax for a short distance is serrate. The body is practically devoid of hairs. From the posterior margin there arise six lanceolate leaf-like appendages with serrate edges. These may be called hairs, are are so represented by Banks, though they are not ordi- 
nary hairs. The palpi are small, and this character, together with the presence of eyes, distinguish this genus from Tetranychus. 'The legs are short and rugose with a few minute scattering hairs. The tarsi end in an expanded portion which is

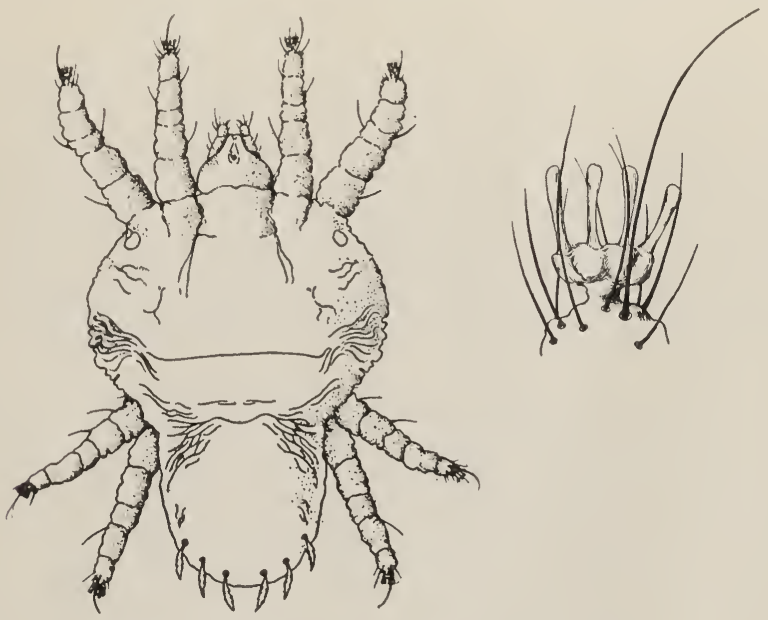

FIG. 8.-Tenuipalpus californicus Banks.

divided into four short clavate hairs. There also arise from the tip of the tarsus one long and a few shorter hairs.

\section{Tetranychoides californicus Banks.}

This species is sometimes found in immense numbers on citrus trees. It is at once recognized by the cast skins being confined to definite areas,

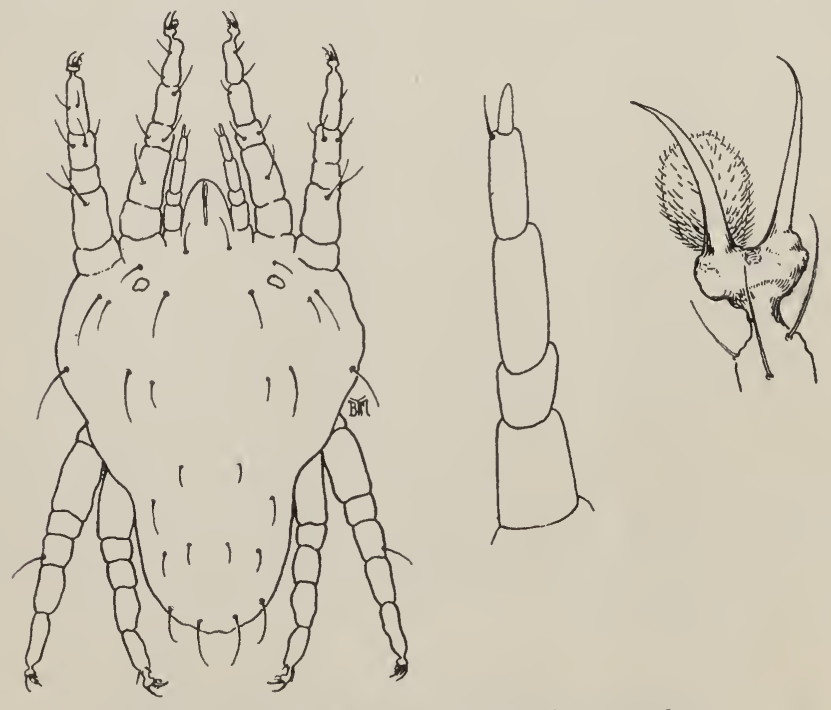

FIG. 9.-Tetranychoides californicus Banks.

usually on the under surface of the leaf. Cast skins of sexmaculatus are congregated in special places also, but these are always covered with 
a web and the leaf surface is of a yellowish color and covered witl black specks. With Tetranychoides the cast skins are arranged in a compact mass and the surface of the leaf is normal. They wander about in their feeding and seem to come to definite headquarters only for the purpose of molting. The injury done by this species is slight as compared with the numbers that may be present.

This mite is of a pale pink color, sometimes being almost white. Body broadest at cephalothorax and then narrowing suddenly. Length .22, width $.13 \mathrm{~mm}$. Rostrum rather broad at tip. Palpi long, five jointed, extending beyond rostrum and tapering to a point, the last joint being small and fiber-like. The tarsi end in two very slightly curved claws between which is an oval-shaped pad covered with numerous short hairs.

\section{Caligonus terminalis Banks.}

This is a red species that has been taken on citrus foliage in San Diego County, usually associated with sexmaculatus. It will be found very often in the colonies with this species and seems to make use of the protective web formed by the latter. It is distinctly red in color, though not as dark a red as mytilaspidis. The body surface is also smooth and shiny instead of velvety. The eggs are red in color, but paler than mytilaspidis. They are spherical in shape and without a stalk. The numbers of this species have never been large and the injury done is not very important.

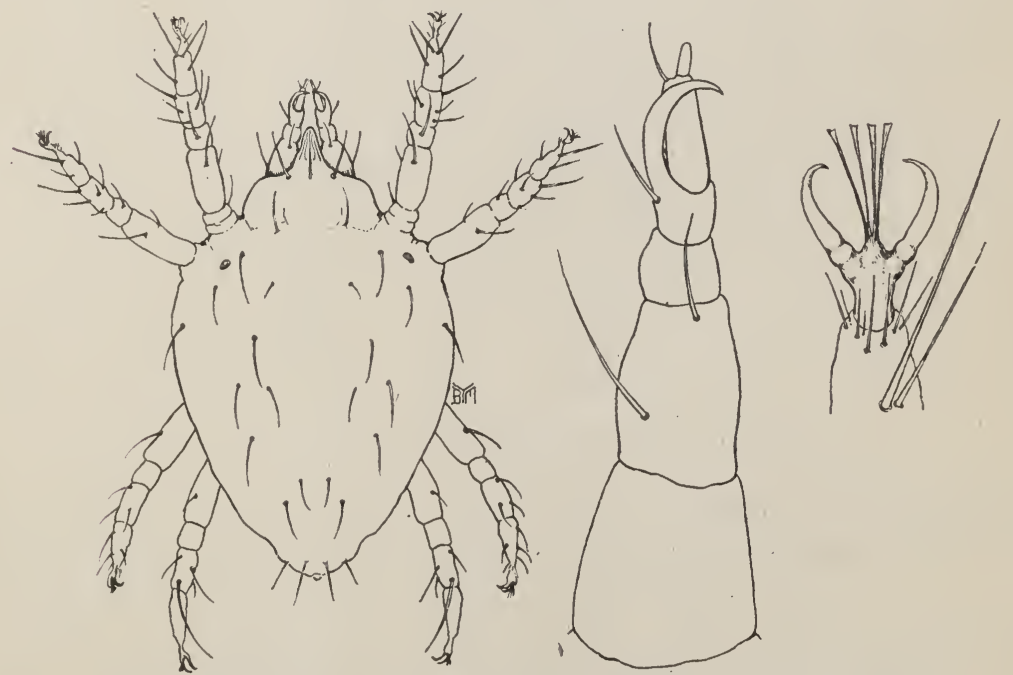

Fig. 10.-Caligonus terminalis Bks. Palpus and tip or tarsus.

Body red. Rostrum, palpi and legs usually yellow. Body surface smooth and shiny. Broad in middle and tapering toward both ends. Length $.3 \mathrm{~mm}$. Greatest width $.14 \mathrm{~mm}$. Twenty-six to twenty-eight hairs clothe the dorsal surface. These are very short and not arranged in definite rows and do not arise from tubercles. 
The palpi are four-jointed, $.11 \mathrm{~mm}$ in length and tapering toward the tip. The thumb is very long, as long or longer than the claw. It extends out straight in the direction of the palpus. From the extreme tip there arises a single finger and a longer hair. The claw is large and very slightly curved: Mandibles rather sharply pointed. Length of fore leg $.22 \mathrm{~mm}$. It is thus slightly shorter than the body. Fourth pair of legs of same length, while second and third pair are somewhat shorter. The tarsi end in two distinct claws which are strongly curved. They are distinctly separated at the base, and from between them there arises a projection which is cleft into four parts.

\section{Tetranychus bimaculatus Harvey.}

This species is only occasionally found on citrus trees and is not strictly a citrus fruit species. Although it becomes very abundant on several different kinds of plants that may be growing near or among citrus, it is only occasionally that it leaves its usual food plants for citrus foliage. Structurally this species is very close to sexmaculatus. The difference is in the number of fingers on the thumb. Sexmaculatus has three fingers at the tip of the thumb while bimaculatus has but one at the tip and one toward the base. But this character seems to be

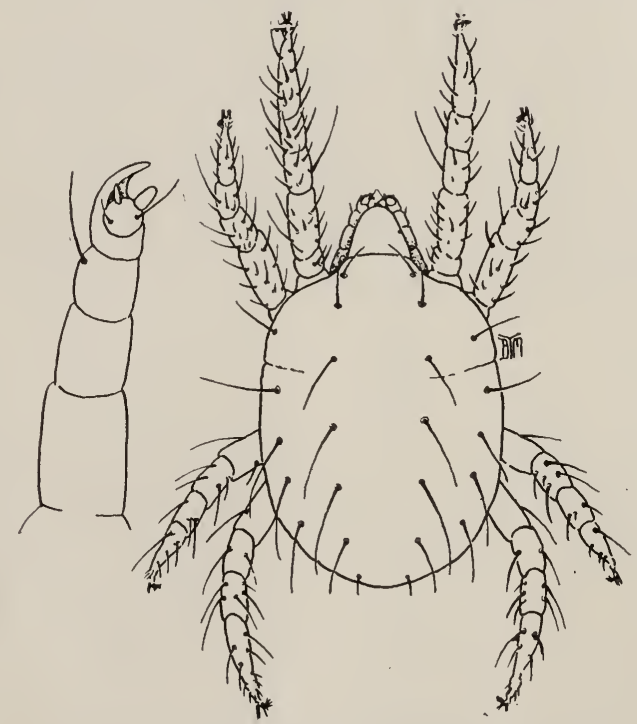

FIG. 11.-Tetranychns bimaculatus Harvey.

variable, and it is sometimes difficult to distinguish the species on this alone. In the latter species there is a red form which is very common and distinct. In the sexmaculatus that occurs on citrus trees this red form has never been seen. Sexmaculatus is limited in its feeding to definite areas, on the citrus tree at least, while bimaculatus on violets, beans and its other common food plants feeds generally over the entire surface. Bimaculatus is the commonest species of spider found in southern California on ornamental shrubs and plants and on certain vegetables, as beans. The total list of its food plants is a very long one. 
In the north central part of the State it is sometimes an important pest on hops. It is a species that has been much written about, and it is not necessary to characterize it in detail here.

\section{Bryobia pratensis Garman.}

This mite is known in the East as the clover mite, since it does most damage to clover and was first described from that plant. In this State it is better known as the almond mite, for it is most injurious to the almond, and occurs throughout the coast valleys and in the interior valleys from Red Bluff to Bakersfield, as well as in southern California. In the citrus section it occurs chiefly on almonds and peaches, and also on vetch that is grown in citrus groves as a cover crop. Although it

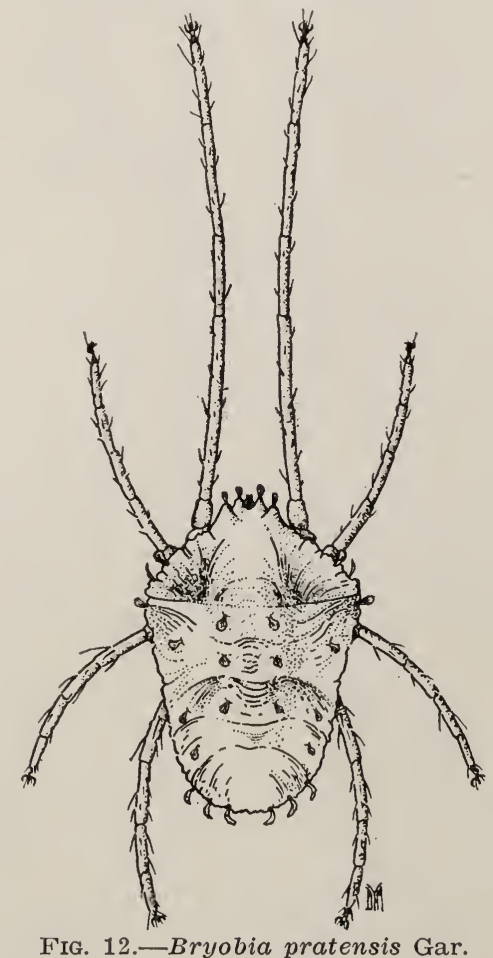

occurs on vetch growing beneath the trees or on almonds growing in the midst of citrus trees, we have never taken it on citrus foliage excepting as it may occur there incidentally.

Bryobia is easily distinguished from other species because of the long fore legs, the four scale-like projections on the front margin of the cephalothorax, and the scale-like hairs on the body itself. It is of a dark color. The winter is passed in the egg stage and on the twigs of almonds, prunes, apricots and other fruits, these red eggs will be found in immense numbers oftentimes. 
Tyroglyphus americanus Banks.

This is a pale colored species that has been taken from lemons in storage. It belongs to the family of Tyroglyphida, several members of

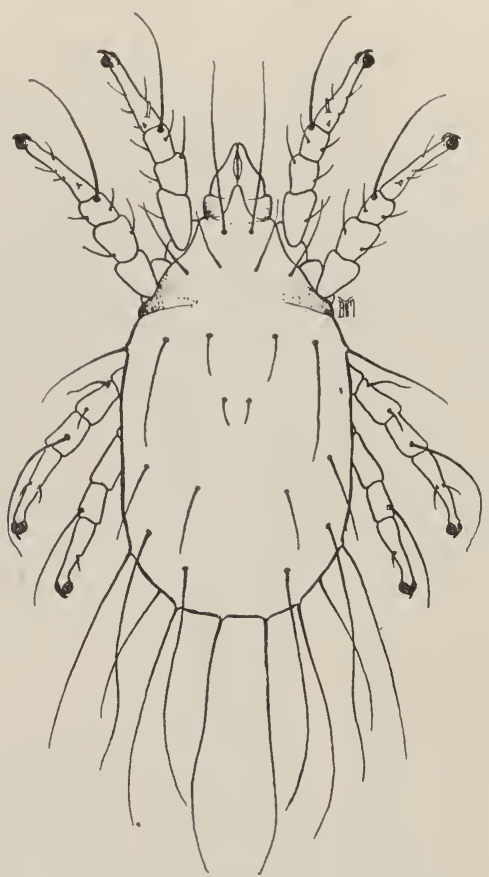

FIG. 13.-Tyroglyphus americanus Banks.

which attack stored foods and the roots and bulbs of living plants. Specimens have been found swarming on lemons in an advanced stage

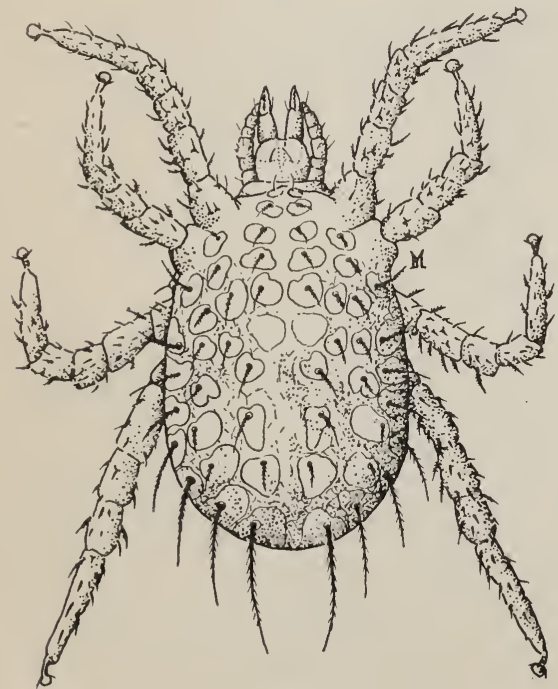

FIG. 14.-Gamasid sp. Predaceous.

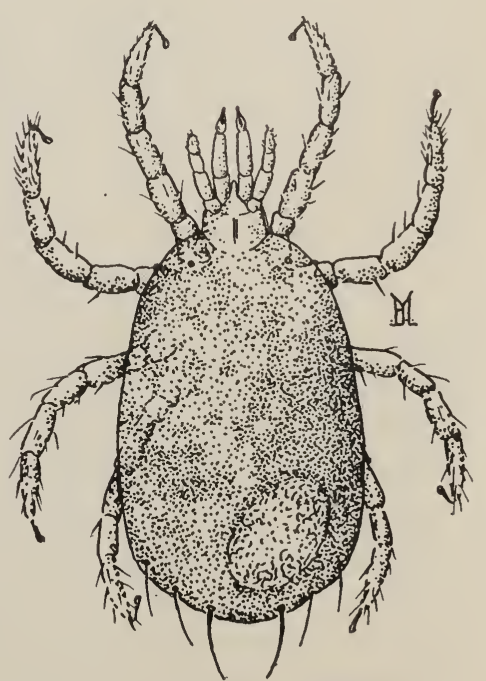

FIG. 15.-Gamasid sp. Predaceous. 
of decay. There seems little doubt that such mites are responsible for the spread of organisms that are responsible for decay. The commonest member of the family Tyroglyphidce in this country is the mushroom mite, $T$. lintneri, which is sometimes very destructive to cultivated mushrooms. The cheese mite, T. siro, is also a related species. Our species may be distinguished by the description which follows:

Pale colored; body elongate; length, .4 mm; width, .22 mm. Clothed with many long hairs. Some of these at the posterior end being about as long as the body. Altogether there are twelve on the posterior margin, two somewhat shorter ones just posterior to a line through the last coxæ, two anterior to these and closer together, a row of six just back of the cephalothorax and another row of four on the cephalothorax. The line separating the abdomen from the cephalothorax is distinct. The tarsi end in a single sharply curved claw and there is also a circular pad or sucker. A long hair arises from the tip of each tibia. On tarsi I and II there is the usual clavate hair which is the distinguishing character of the family. But on tarsi I there is an additional clavate hair very much smaller than the other and nearer the tibia and outward from the larger one. The mandibles are chelate. The palpi are very small and appear to arise from the sides of the rostrum. This species is near $T$. lintneri, but the arrangement of the hairs is different, the feathered ones are not present on legs I and II and the presence of the additional clavate hair on tarsi I seems to make it distinct.

\section{Gamasid sp.}

This species was associated with Tyroglyphus on the stored lemons and was present in about equal numbers. It is a predaeous species. The character distinguishing it from all other species of mites taken on citrus fruits is the presence of feathered hairs over the body. The species is characterized as follows:

Pale colored body, oval in shape, slightly broaded behind; length, $.33 \mathrm{~mm}$, width, $.26 \mathrm{~mm}$; fore legs equal to length of body; others slightly shorter. Body covered with many short plumose hairs. These hairs are arranged regularly in eight rows. Around the base of each hair is a smooth area with a definite outline giving the surface the appearance of being made up of many plates. These areas are of a definite shape, many having a constriction, while some appear to be distinctly double, the separation being made by the constriction. 'The hairs are stiff and slightly curved with five plumose hairs arising from the surface. The cephalothorax ends anteriorly in a rounded projection from which arise two short plumose hairs. The palpi are large, five jointed, the last joint bearing a divided claw near the tip on the inner margin, while several hairs arise from the extreme tip. The mandibles are long and chelate. The mandibular plate broad, with a marked constriction at the center. The tarsi end in an expanded portion from which arises a circular pad, which is supported by two minute claws that extend at right angles to the axis of the tarsus.

Tarsonemus approximatus Bks. Mss.

This is an exceedingly small mite that is occasionally met with on citrus trees. It has been taken from the foliage, and from under scale insects. The latter situation has aroused some suspicion that they may be feeding on the eggs of such scale insects as the black and purple, although the usual habits of the group are as vegetable feeders and some are credited with doing considerable injury to grasses, tea, pineapples, and greenhouse plants. T. assimilis Bks. Mss. was also taken on citrus.

A very minute species, length, $.13 \mathrm{~mm}$; width, $.08 \mathrm{~mm}$; oval in shape and devoid 
of hairs excepting on the legs and a few at the tip of the body. The rostrum is cone shaped. The palpi are inconspicuous and closely oppressed to the sides of the rostrum. The clavate organ between the first and second pairs of legs is conspicuous, being very broad and oval-shaped at the tip. This clavate organ of unknown use is the distinguishing character of the family Tarsonemida. The line separating the cephalothorax from the abdomen is fairly distinct. The legs are short and end in two minute claws and also a pad. The fourth pair in the female are more slender and
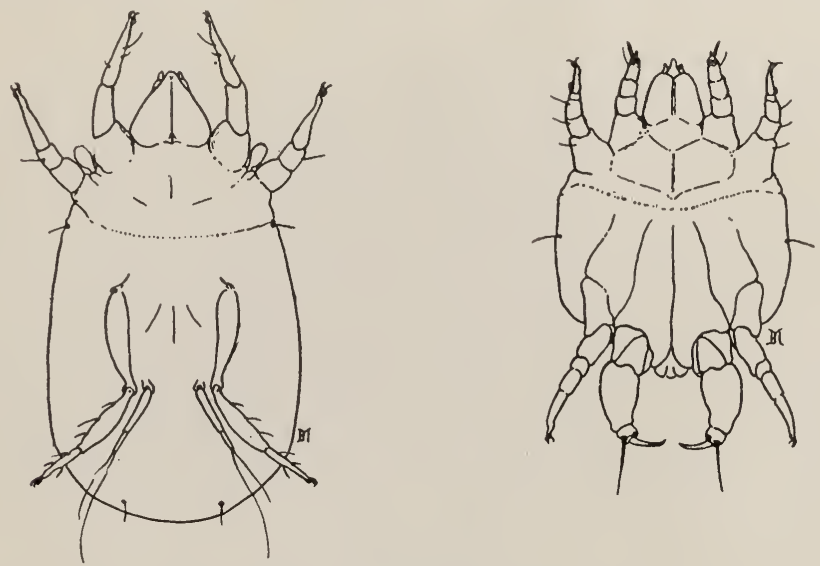

FIG. 16.-Tarsonemus approximatus Bks. Mss.

whip-like, ending in two long threads, one of which is considerably longer than the other. The fourth pair of legs in the male are very stout and end in a single large curved claw. One or two smaller spines or hairs arise from the base of the claw on the inner side, while a very long hair extends outward. The body of the male is also much shorter and broader than that of the female. The single claw on the fourth tarsus of the male distinguishes it from any of the species figured in Banks monograph.

\section{Eremaeus modestus Bks.}

This species is one that has not been noted to affect the foliage or fruit of the orange, but has been seen in immense numbers on the trunk

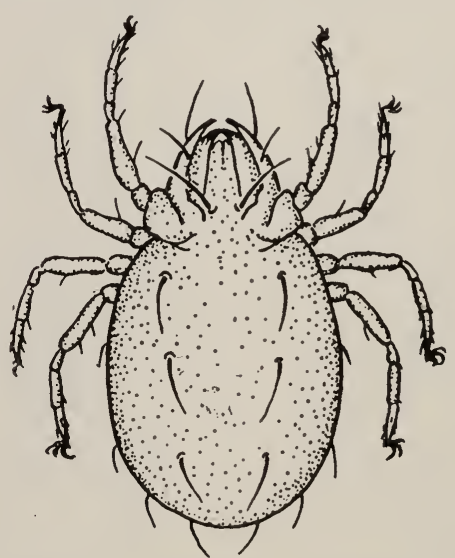

FIG. 17.-Eremaeus modestus.

and large branches. They have the habit of congregating in compact masses as close as it is possible for them to pack together. Such masses 
have been seen to extend for several feet up and down the branches and to contain countless millions of mites. These were probably feeding on the lower forms of plant life that were growing on the bark of the tree, as certain forms of algæ which give a green coating to the bark.

This species belongs to the family Orbatidce, or "beetle mites," so called because the body covering is hard and coriaceous. It is of a dark brown or black color and pointed at the anterior end. Other species of this group have been found in damp situations such as on flower pots that have been kept in the ground. The species mentioned above was found on large trees that afforded plenty of shade and it was also during the winter season.

Key to the Species of Red Spiders and Mites recorded in this Bulletin.

(Partially adapted from Banks.)

1. 1. Abdomen annulate; minute form . . Silver mite, Eriophyes oleivorus

2. Abdomen not annulate . . . . . . . . . .

3. Body coriaceous . . . . . . . Eraemus modestus

4. Body not coriaceous . . . . . . . . . . 5

5. With clavate organ between legs I and II in the female Torsonemus sps.

6. Without such clavate organ

7. With clavate hair on tarsi I and II . . Tyroglyphus americanus

8. Without such clavate hair . . . . . . . . .

9. Front legs twice as long as the body . . . . Bryobia pratensis

10. Front legs not twice as long as body . . . . . . . 11

11. Palpi ending in a distinct thumb and with claw . . . . . 17

12. Palpi without thumb and claw . . . . . . . . . . . . 13

13. Mandibles chelate . . . . . . . . Gamasid sps.

14. Mandibles not chelate . . . . . . . . . . 15

15. Palpi very small, legs short, rugose . . Tenuipalpus californicus

16. Palpi rather long and slender, legs longer and not rugose

Tetranychoides californicus

17. Bristles of body arising from tubercles . Tetranychus mytalispidis

18. Bristles of body not arising from tubercles . . . . . 17

19. Tarsus with two claws . . . Caligonus terminalis

20. Tarsus with but one claw . . . . . . . . . . 19

21. With three fingers at tip of thumb, color never red

T'etranychus sexmaculatus

22. With one finger at tip of thumb and one nearer base. Red forms often occurring

Tetranychus bimaculatus

\section{NATURAL ENEMIES.}

Red spiders and mites, exposed as they are throughout their lives on the surface of the leaves or fruit, are subject to the attacks of a considerable number of enemies. But in the course of our investigation the number has not been so striking as the unusual variety of their enemies. We commonly think of thrips as plant enemies rather than predaceous insects. Members of the family Itonidoe (Cecidomyiidae) are better known on account of their gall-making habits and attacks on living plants rather than as parasites. Most of the Staphylinid beetles feed on decaying vegetable and animal matter, while a much smaller number 
are known to be predaceous. While all members of the family Coniopterigidce are predaceous, they are such rare insects and so little known about them that they are no less interesting than the others mentioned. Aside from these, there are the usual Coccinellids, Hemerobiids, Crysopids, and mites, and as a hyper-parasite, a chalcid. The natural enemies of our citrus spiders thus include the classes, Acarina and Insecta, and in the latter class the following orders: Neuroptera, Thysanoptera, Coleoptera, Diptera, and to include the hyper-parasite, the Hymenoptera.

While many of the following predaceous insects were found feeding on the six-spotted mite and others, most of the observations were made on the citrus red spider, and the following statements have reference to this species.

\section{Conventzia hageni Banks.}

This species is one of the commonest enemies of spiders of citrus trees in the southern California citrus sections. It belongs to the family Coniopterygidce of the order Neuroptera. These include the smallest insects of the order. There are also very few representations of the family in the country and only two species in California. They are related to the Hemerobiids and Crysopids. The above species feeds on the red spider, both in the larval and adult stages.

LIFE HISTORY AND HABITS.

The Egg.-The egg is pinkish yellow in color and oval in shape, measuring $.5 \mathrm{~mm}$ long and $.23 \mathrm{~mm}$ wide. The surface is marked with

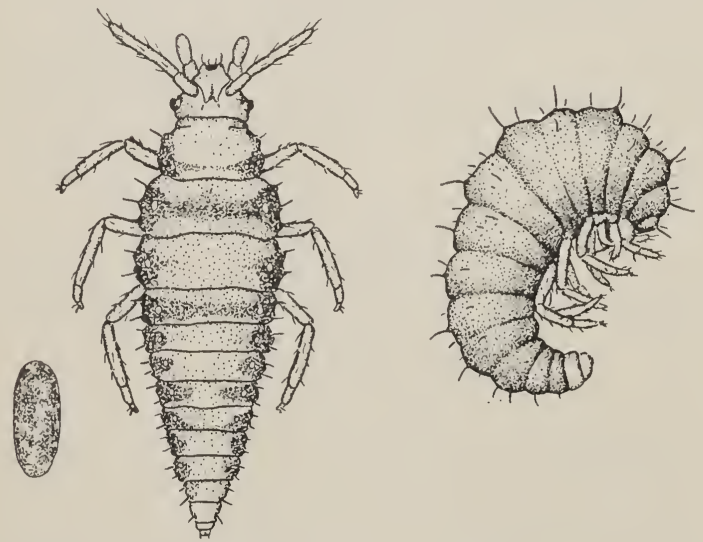

Fig. 18.-Conventzia hageni Banks. Eggs, larva, pupa. Feeds on Red Spiders.

hexagonal reticulations. The eggs are deposited singly, usually on the under surface of the leaf. From six to eight days are required for the egg to hatch. 
The Larva.-The body of the larva is broad at the anterior end, becoming still wider at the thorax and then gradually tapering toward the posterior end. The color and markings vary considerably, but the

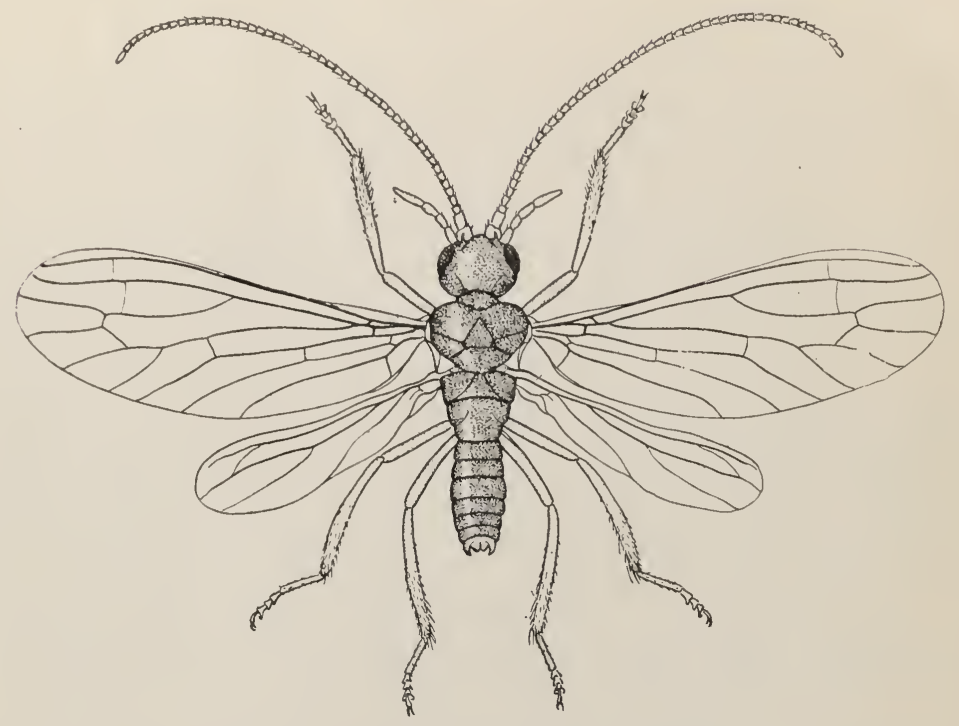

FIG. 19.-Conventzia hageni Banks.

usual colors are white, red, and black. The white is present along the margins, and it also extends inward in variable blotches on each of the segments. There is also a more or less regular line of white on the
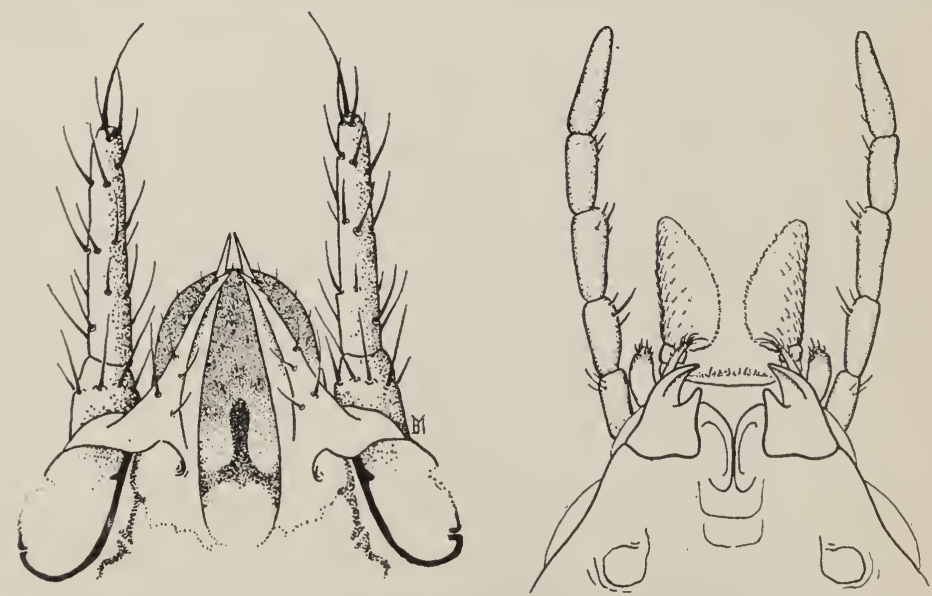

FIG. 20.-Conventzia hageni Banks. Mouthparts of larva on left. Mouthparts of adult on right.

median dorsal line. The antennæ consist of one short and one long joint, both clothed with hairs. The mouth parts consist of a coneshaped beak enclosing the needle-like mandible and maxillæ, the latter being serrate at the tip. The palpi are broad, spatula-shaped append- 
ages that extend out on either side like two large ears. From the blunt ends of the tarsi there arise two curved spurs.

The larva undergoes three molts during its period of development, which require an average of fifteen days. The first molt occurs four days after hatching, the second ten days after hatching, and the third on the fourteenth or fifteenth day. Six days later it begins to spin its cocoon so that the total larval period is from eighteen to twenty-two days.

The larva feeds on all stages of the spider, including eggs, young and adult. In attacking the eggs the mandibles are thrust through the egg membranes on the lower side near where it is resting on the surface. The entire contents are thus consumed generally from a single puncture. The egg is changed from a bright red or pink color to a transparent shell. Ten or fifteen seconds is sufficient time for an egg to be consumed. The contents of the spiders themselves are similarly absorbed, except that it requires a longer time and the puncture is not always made low down. From four to seven minutes are required for taking out the body contents of the larger spiders. These are reduced to a small crumpled mass with a small amount of the red pigment still present.

The capacity of the Coniopteryx larva for feeding is shown in the table below. From this it will be seen that one larva consumed 96 spiders in sixteen days; another a total of 226 spiders for its development from hatching to pupation; another 136 in eleven days; another 253 for its whole larval period; and another (not in the table) 53 spiders in three days.

Conventzia hageni Banks.

Feeding of Larva.

\begin{tabular}{|c|c|c|c|c|c|c|c|c|c|c|c|c|c|c|c|c|c|c|c|c|c|c|}
\hline \multirow{2}{*}{\multicolumn{2}{|c|}{ Larva No. }} & \multicolumn{18}{|c|}{ Spiders consumed. } & \multirow{2}{*}{$\stackrel{\overrightarrow{0}}{\stackrel{\vec{D}}{\vec{t}}}$} & \multirow{2}{*}{ 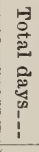 } & \multirow{2}{*}{ 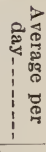 } \\
\hline & & $\begin{array}{l}\vec{b} \\
\stackrel{2}{+} \\
\stackrel{0}{0} \\
\dot{0} \\
\vdots\end{array}$ & $\begin{array}{l}0 \\
2 \\
2 \\
20 \\
\vdots \\
1\end{array}$ & $\begin{array}{l}\mathscr{c} \\
2 \\
\tilde{y} \\
\vdots \\
1\end{array}$ & $\begin{array}{c}\text { 芦 } \\
0 \\
0 \\
\vdots \\
\vdots \\
\vdots\end{array}$ & $\begin{array}{c}\text { J } \\
\overrightarrow{5} \\
\stackrel{0}{0} \\
\vdots \\
\vdots \\
\end{array}$ & 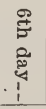 & 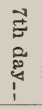 & $\begin{array}{c}\infty \\
\vdots \\
\vdots \\
\stackrel{2}{4} \\
\vdots \\
1\end{array} \mid$ & 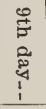 & 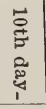 & 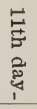 & 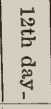 & 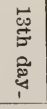 & 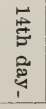 & $\begin{array}{l}\vec{c} \\
\vec{J} \\
0 \\
\stackrel{0}{0} \\
1\end{array}$ & 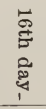 & $\begin{array}{l}\overrightarrow{1} \\
5 \\
5 \\
\tilde{\Xi} \\
1 \\
1\end{array}$ & $\begin{array}{l}\infty \\
\stackrel{\infty}{\sigma} \\
\stackrel{0}{0} \\
\stackrel{0}{4}\end{array}$ & & & \\
\hline 1 & & 3 & 5 & 9 & - & -5 & 12 & $\mathrm{~m}$ & 13 & 15 & 19 & 25 & 25 & 25 & 25 & 25 & 25 & & & $\begin{array}{l}226 \\
136\end{array}$ & $\begin{array}{l}16 \\
11\end{array}$ & $\begin{array}{l}15 \\
12\end{array}$ \\
\hline $\begin{array}{l}2 \\
2\end{array}$ & - & $\begin{array}{r}20 \\
2\end{array}$ & $\begin{array}{l}--- \\
---\end{array}$ & $-\cdots$ & $\mathrm{m}$ & $\begin{array}{l}25 \\
13\end{array}$ & 15 & $\begin{array}{l}25 \\
25\end{array}$ & $\mathrm{~m}$ & $\begin{array}{r}16 \\
9\end{array}$ & $\mathrm{~m}$ & $\begin{array}{l}25 \\
25\end{array}$ & 25 & 25 & 25 & 25 & 25 & 25 & 23 & $\begin{array}{l}100 \\
262\end{array}$ & 18 & 15 \\
\hline
\end{tabular}

Pupation and the Cocoon.-When fully mature the larva selects a place on the under side of the leaf, usually along the midrib, but occasionally on other parts of the leaf where there is some little protection. Where the six-spotted mite is attacked the depressions formed by this species are a very common place chosen. The thread is emitted at the posterior end and the movements in spinning the web describe a figure 8. 
The cocoon consists of a double layer of silk, an inner compact layer more or less oval in shape and an outer flat, loosely woven web. This outer covering extends out beyond the inner cocoon and makes it appear very flat on the leaf. These cocoons are nearly always to be found on the under side of the leaf and they look not unlike the masses of Psocid eggs with their silken covering, or like some of the masses of the smaller spiders' eggs. The diameter is about $6 \mathrm{~mm}$, and an examination for the double layer of silk will at once distinguish the cocoons of this insect.

The Pupa.-The pupa is of a reddish brown color. The head is deflexed and the appendages lie fairly close to the ventral surface. The time spent in the pupal stage is thirteen days, the period varying but a day or two from this on all of which records were made.

The Adult.-When the transformation to the adult occurs within the cocoon the insect emerges by pushing out on its side usually through the outer cocoon, at the same time splitting the inner cocoon. When partly out, after resting for a short period, it crawls out by pulling itself along with its legs, which by this time are freed.

The mature insect is a small, very frail insect, about one fifth of an inch long and of a grayish white color. The wings are covered with a grayish powder and members of this group are called dusty wings. The second pair of wings are very small as compared with the fore wings. The antennæ are long and beadlike, consisting of many joints. There are a pair of five-jointed and a pair of three-jointed palpi arising from the mouth. The tarsi are made up of five joints, the third being very short and broad.

\section{Oligota oviformis Casey.*}

This species is one of the Staphylinida or rove beetles. According to Dr. Fenyes it is taken occasionally from the flowers of the Christmas berry, and also from the leaves of the live oak, where it probably feeds on small Arthropods. We have found the species feeding on the red spider in both the larval and adult stages. They were taken on citrus trees from Los Angeles to San Diego, sometimes occurring in large numbers. March, April, May and June were the months when they were most common. The larva is long and slender and the adult is a peculiarly shaped black beetle with the head pointing downward and the tip of the abdomen sticking upward.

\section{DESCRIPTIONS-LIFE HISTORY-HABITS.}

The Egg.-The egg is of a light orange color, oval in shape and with a slightly reticulate surface. The length is $.36 \mathrm{~mm}$ and the width $.25 \mathrm{~mm}$. They are laid singly on the under surface of the leaf. Hatching occurs in seven to nine days.

*Casey, Ann. N. Y. Ac. Sc. VII, p. 381, 1893. Described as Somatium oviforme. 
The Larva.-The length of the full grown larva is about $2.5 \mathrm{~mm}$ and the width $.6 \mathrm{~mm}$. It is narrower at anterior end and widens posteriorly; color yellow. The clothing consists of hairs scattered about in a more or less irregular manner, but on the abdominal segments there is a definite row on each. The antennæ consist of three joints, the middle joint being longest with a prominent finger on the outer shoulder. The last joint is much narrower than the preceding and ends in a straight spine. Three long hairs arise from the tip of segments 2 and 3. The maxillary palpi consist of three joints which taper to a point. The labial palpi are similar in shape but much shorter. The mandibles are
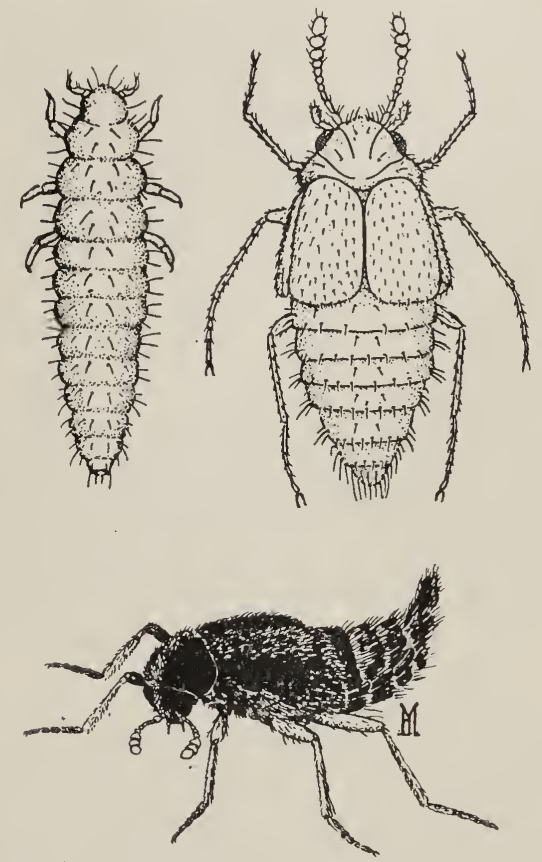

FIG. 21.-Oligota oviformis Csy. Larva and adult. Characteristic position of adult shown below.

sharp-pointed and curved. From each of the tarsi there arises a single, very slightly curved, rather long claw.

Manner of and Capacity for Feeding.-With its sharp pointed mandibles the larva punctures the spider usually about the center of the body, and by a pump-like action the body content is sucked up. This is colored red and may be distinctly observed passing from the body of the spider into the alimentary canal of the more or less transparent larva of Oligota. As most of the body juices of the spider were absorbed they were spewed back again, and the spider, which had been made transparent by the absorption of the body contents, resumed its normal color and rigidity. This pumping back and forth is repeated two or 
three times before the mouth parts finally release the victim. Feeding also occurs on the eggs in a similar manner.

The capacity of the Oligota larva for feeding is considerable, as our records show an average of about twenty spiders consumed each day. This, too, includes a majority of the more fully mature spiders since they were transferred daily and consequently the eggs and small spiders would be left. Twelve to fifteen days represent the longest period we have been able to get the larva to live. That is, repeated efforts have failed to bring it to the pupal stage, although our maximum records carried them to a stage just preceding pupation. But counting the time that has actually been observed, the larva will consume upwards of two liundred or three hundred spiders during the course of its development.

The Adult.-The adult Oligota is a small black peculiarly-shaped beetle with short wing covers and with the abdomen strongly curved upward. The head is bent under and vertical and not visible from above. The antennæ are yellow and consist of ten segments. Are club shaped with first two joints longest, next five short and small, while the last three are much broader and bead shaped. The abdomen is pointed. Body densely clothed with hairs. Length $1 \mathrm{~mm}$, width $.57 \mathrm{~mm}$.

While the adult of this species does not eat so many spiders each day as the larva, the longer life of the adult makes the total number consumed about equal. The adults require about ten spiders a day and the maximum adult life determined was thirty-two days, making a total of 320 spiders consumed. A pair of beetles were placed in a cell on March 19th and furnished with spiders for food. On March 22d egg laying was begun and the first larva hatched on April 1st. There were but four larvæ hatched in all and these lived fourteen days. The last adult died on May 2d. The total number of spiders consumed in this experiment was 792 .

\section{Stethorus picipes Csy.}

This species was the commonest coccinellid or lady beetle that was found to feed on the red spider. It was generally distributed over the citrus section, having been taken in Los Angeles, Orange, Riverside, San Bernardino, and San Diego counties. It was most abundant of all the enemies in Riverside and San Bernardino counties.

DESCRIPTIONS-LIFE HISTORY-HABITS.

The Egg.-The egg of this coccinellid is oval in shape and pinkish yellow in color when first deposited, but as hatching time approaches it turns black or dark gray. The surface is marked with hexagonal reticulations. The eggs are deposited singly, usually on the under surface of the leaf. The total number of eggs deposited of which we have certain records is 21 , though this number may be exceeded under perfectly 
natural conditions. The hatching period is seven or eight days during the month of April.

The Larva.-The length of the larva is $1 . \mathrm{mm}$ (1/25 of an inch) and the width $.55 \mathrm{~mm}$. The color is dark gray to black. The body is clothed with numerous hairs arising from small tubercles. In addition to these longer hairs the entire surface is covered with short spines, those along the folds of the skin being larger and darker in color.

The young larva emerges from a longitudinal rent in the eggshell. It is at this time of a mottled grayish yellow and black color. A larva that hatched on March 1st molted on the 7th and 20th and pupated on the 30th, making the total larval life thirty days. Another hatched on May 1st, molted on the 8th and 13th and pupated on the $23 \mathrm{~d}$, a total of twenty-three days. These, together with other records, give the length
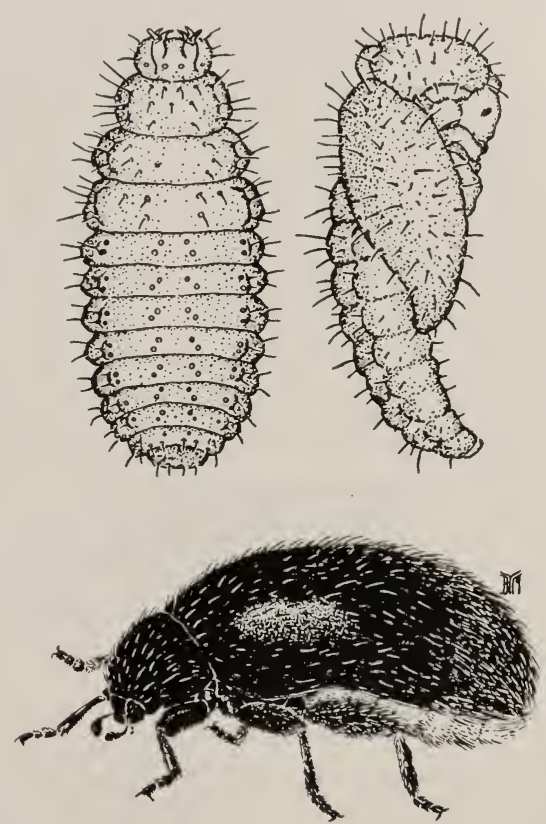

FIG. 22.-Stethorus picipes Csy. Larva, pupa, adult. Feeds on Red Spider.

of minimum larval development as twenty-one days and the maximum thirty days.

Feeding records show that, in the case of one larva that lived thirty days it consumed a total of 189 spiders, or an average of 6 or 7 per day. Another larva devoured a total of 110 spiders in thirteen days or an average of $8+$ per day. Records on this larva were made during the latter half of the development period.

The Pupa.-Pupation occurs on the under side of the leaves, the pupa being dark colored, about $1 / 20$ of an inch long, and of the usual 
coccinellid appearance. One pupated March 16th, emerged March 21st. Another pupated April 10th and emerged April 17th.

The Adult.-The adult is a polished black beetle clothed with fine hairs and about $1 / 20$ to $1 / 25$ of an inch long. The antennæ are eleven jointed, with the last three joints of the small club equal in length. The original description of this beetle will be found in the Jour. N. Y. Ent. Soc., volume VII, page 136.

\section{THRIPS.}

(Scolothrips sexmaculatus Pergande.)

Most species of thrips are plant feeders, and there are several species occurring in the State that are important pests. There are, however, a few species that are known to be carnivorous, though the records on such habits are very fragmentary, with the exception of the above species, which has been observed by Pergande and Bruner to feed upon red spiders and mites. We have repeatedly observed the above species to feed on the citrus red spider. It occurred most abundantly during the winter and early spring. For the most part the eggs and younger

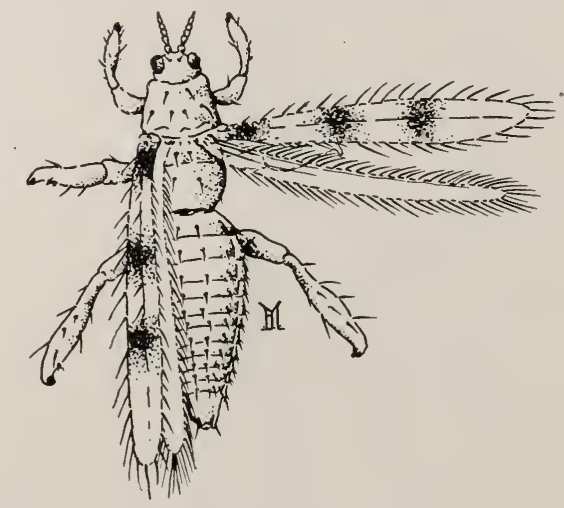

FIG. 23.-Scolothrips sexmaculatus Perg. Feeds on Red Spider.

spiders are attacked, though occasionally the fully mature spiders are eaten. The time required to consume the contents of eggs and spiders varied from three to seven or eight minutes. Most of the contents of the egg were taken from a single puncture, then two or three additional punctures would be made on different sides and close to the bottom, to get what little of the contents remained. The eggs were thus rendered perfectly transparent, nothing but the shell remaining.

In the case of the spiders themselves, after taking most of the body contents, the spider would be rolled around and punctured from different sides, the revolving being done by the fore legs of the thrips. The spiders were attacked mostly before the first or second molt, and usually 
at a time when the spider was in a quiescent stage just preliminary to the molting process. In coming in contact with the largest spiders the thrips would sometimes quickly retreat, and in one case it was observed to assume the attitude of the praying mantis, with the fore part of the body elevated and fore feet extending downward from knee. In a few cases, however, the adult thrips have been seen to attack a full-grown female of T. mytilaspidis. One of these requires one hour and ten minutes to suck out all of the body contents. All stages of the thrips, barring the pupa, have been noted to feed on the red spider.

The general color of this species of thrips is pale yellow, with three light brown spots on the fore wings. The antennæ are eight jointed, the sixth joint being the longest. The first and second joints are light colored while the others are dusky gray.

\section{Arthrocnodax occidentalis Felt MMS.}

This is a species of Itonidæ (Cecidomyiida), the larva of which has been found to feed on the red spider. This enemy of the spider was taken in widely separated localities, as Whittier and San Diego, and
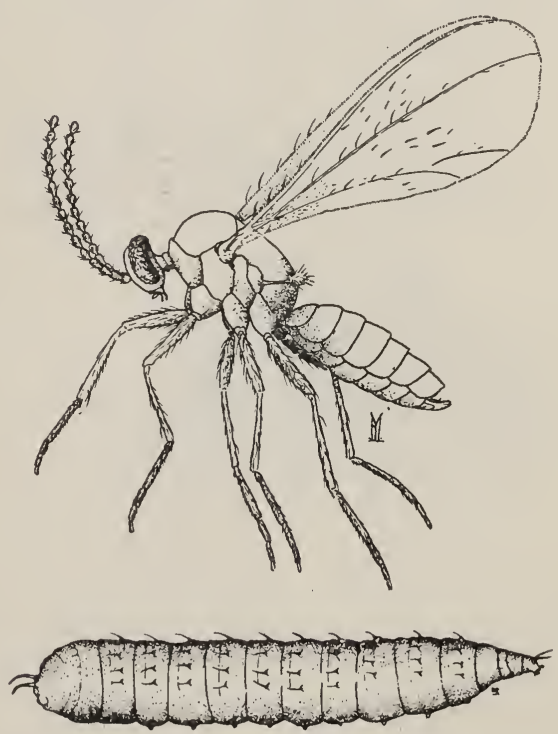

FIG. 24.-Larva and adult of Arthroconodax occidentalis Felt MMS. Feeds on Red Spiders.

appears to be very generally distributed. It has been observed to feed on mytilaspidis, bimaculatus, and sexmaculatus. On the last species it was taken in considerable numbers in San Diego County. The definite colonies, together with their protective covering of web that characterizes sexmaculatus, seem to offer the best conditions for this dipterous larva. 
Not having great powers of locomotion, it finds the spiders massed in a colony decidedly to its advantage in the capture of food, and, as shown later, since it is subject to the attacks of a parasite the covering of web serves to protect it from such attacks.

The following description will enable the larva of this predatory Cecidomyid to be identified: Length $2.2 \mathrm{~mm}$, width, .43 mm, color yellow. Head end narrow, ending in a pair of two-jointed palpi or antennæ. The first joint is very broad and short and should scarcely be called a joint, though two-jointed palpi are a family characteristic according to Williston. The second joint is straight and spine like. There are fourteen body segments and on the fifth to the thirteenth, inclusive, are a pair of nipple-like stigmata. Extending around each segment is a row of short spines and on the last segment are two curved spines. In the earlier larval stages there are three pairs of caudal spines, one small

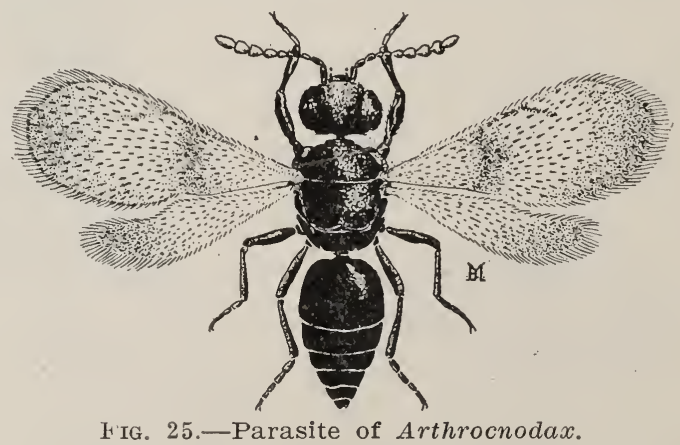

pair in the center, which is the pair that evidently persists in the last larval stage, and a much larger pair on either side.

Where the number of these larvæ is large their effect on checking the spider is considerable. One on which records were kept consumed 165 spiders during a period of fifteen days. Another had 380 spiders to its credit during a period of seventeen days.

The egg is long, narrow, and sickle shaped and of a brownish yellow color. Length .26 mm. They are laid singly on the under side of the leaves.

The cocoon is spun on the surface of the leaf, usually on the under side. It is a rather flat, oval, compact mass of silk. Upon emerging the pupal skin is left protruding nearly its full length from the cocoon.

The species was sent to Dr. Felt, of New York, who identified it as probably a new species of Arthrocnodax, and has since described it as Arthrocnodax occidentalis. 
Thriphleps insidiosus Say.

This is a carnivorous bug belonging to the family Anthocoride. With its large beak or proboscis which is thrust into the spiders, the body contents are soon consumed. Both the nymphs and adults feed on the spiders. This species was not at all common during the past year and therefore was of little aid in checking the spiders. If its numbers were large a great many spiders would be devoured for its capacity for feeding is considerable. The species may be identified from the figures. It is a small bug, one twelfth of an inch long and of a black color.
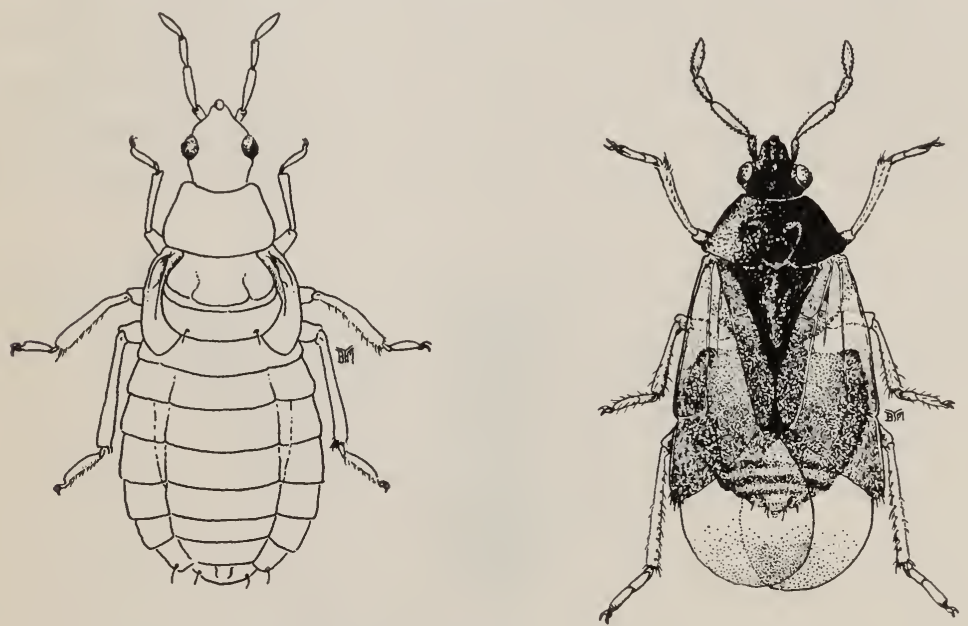

Fig. 26.-Thriphleps insidiosus. Feeds on Red Spiders.

\section{The Brown Lacewing.}

The larva of this species is very voracious and eats a large number of spiders during its development. Unlike many of the other enemies, however, it is not restricted in its feeding to spiders and mites. Records on the feeding of two of the brown lacewing larva are given below.

\begin{tabular}{|c|c|c|c|c|c|c|c|c|c|c|c|c|c|c|c|c|c|c|c|c|}
\hline 5 & \multirow[b]{2}{*}{ Hatched. } & \multicolumn{17}{|c|}{ Spiders provided for food. } & \multirow{2}{*}{ 혈 } & \multirow{2}{*}{ 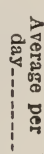 } \\
\hline & & $\begin{array}{c}\vec{p} \\
\stackrel{a}{a} \\
\stackrel{0}{0} \\
\vdots \\
1\end{array}$ & 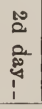 & $\begin{array}{l}\infty \\
2 \\
0 \\
\infty \\
\vdots \\
\vdots \\
1\end{array}$ & $\begin{array}{c}\stackrel{c}{5} \\
0 \\
0 \\
0 \\
1 \\
1\end{array}$ & 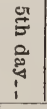 & 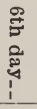 & $\begin{array}{l}\text { है } \\
0 \\
\text { हैं }\end{array}$ & 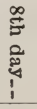 & $\begin{array}{l}0 \\
\vdots \\
\circ \\
0 \\
\vdots \\
\vdots\end{array}$ & $\begin{array}{l}\vec{\circ} \\
\stackrel{5}{5} \\
2 \\
\stackrel{2}{4} \\
1\end{array}$ & $\begin{array}{l}\vec{E} \\
\vec{E} \\
2 \\
\overrightarrow{0} \\
\dot{y}\end{array}$ & 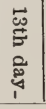 & 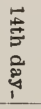 & $\begin{array}{l}\overrightarrow{0} \\
\overrightarrow{0} \\
0 \\
0 \\
0 \\
0\end{array}$ & 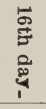 & 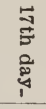 & $\begin{array}{l}\text { 18th, 19th } \\
\text { and 20th } \\
\text { days. }\end{array}$ & & \\
\hline & April $4 \ldots$ & 25 & 22 & 25 & $\ldots$ & 25 & 25 & 50 & 50 & 50 & 50 & & 50 & 35 & 50 & 50 & 100 & escaped & 532 & \\
\hline & April 4 & 25 & 25 & $-\cdots$ & 47 & 25 & 50 & 50 & 50 & 50 & $-\cdots$ & 50 & 42 & 8 & 50 & 100 & 100 & 300 dead & $\$ 97$ & \\
\hline
\end{tabular}

This gives a total of 532 spiders consumed in seventeen days, when it escaped, for one larva, and a total of 897 in twenty days for the other, when it died, although this one was no doubt mature and ready for pupation. The spiders are caught and impaled on its long lance-like mandibles and the body contents absorbed. 
The egg of this lacewing is ovoid in shape, $.8 \pm \mathrm{mm}$ long and white in color. The surface is marked with spiral reticulations, and at one end is the small knob-like micropyle. The eggs are laid singly on the under surface of the leaf.

The larva has the typical appearance of Chrysopa or Hemerobius larva with its large sword-like mouth parts. While Hemerobiid larvæ have been given certain general characters, such as width of head and shape of body, that distinguishes them from Chrysopa larvæ, this is not sufficient to warrant a positive determination. In such literature as we have at hand there are certain structures on the feet of Chrysopida that are described as peculiar to this family. This structure is a very prominent, trumpet or elongate bell-shaped sucker, situated between the claws. But we find this present also on the feet of the larva of the brown lacewing, so that it is not limited to the Chrysopida alone. The antennæ of the brown lacewing larva are composed of three joints and the whole is distinctly annulate. The rings are very close together and each is not

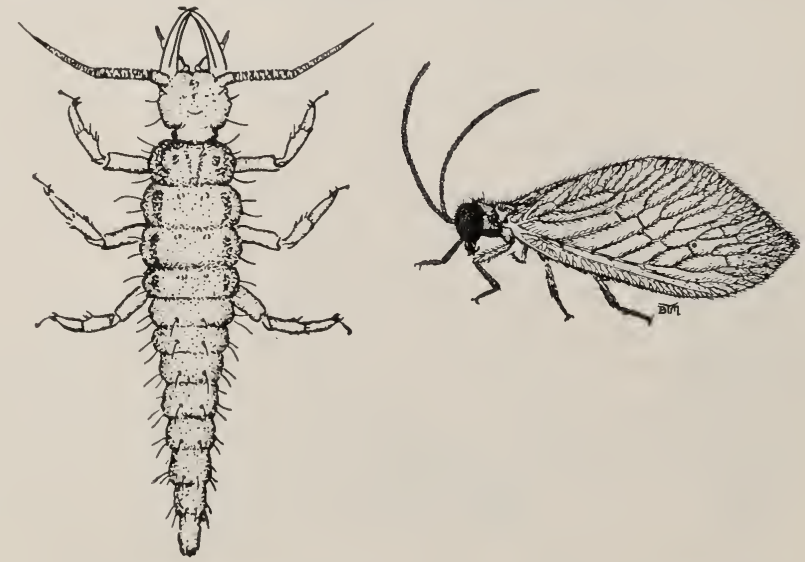

FIG. 27.-Brown Lacewing. Hemerobius pacificus Banks. Feeds on Red spider.

distinct so that several cross lines occur connecting the different rings. In the larva of the Chrysopa which has been associated with the brown lacewing on citrus trees, the antenna is not made up of three distinct joints. There is a short, broad, basal joint similar to the corresponding one in the brown lacewing. At about two thirds of the way to the tip there is in the Chrysopa a distinct shoulder where the antennæ suddenly narrow. Arising from this shoulder, which is probably a sensory pit, there is a short stout spine. But there is no evidence of a distinct joint, and the outer surface at this point is not interrupted. In Chrysopa the basal part is made up of rings that are distinctly farther apart than those more distal. Indeed these longer rings on the basal half of the antennæ of Chrysopa are, in the two species concerned, the most prominent distinguishing characters. 
The cocoon consists of a very thin, loosely woven layer of silk which is formed on the leaf surface, usually the under side. The cocoon is, thus, very different from its ally the Chrysopa, which consists of a very definite and compact cocoon.

The adult of this species is distinctly brown in color and about two fifths of an inch long to the tips of the wings. The antennæ are made up of numerous bead-like joints. The entire insect is clothed with short brown hairs. The life eycle requires about fifty days. The egg stage lasts about eight days, the larval life is twenty days and twenty days are spent in the cocoon.

\section{The Green Lacewing.}

This is the commonest of the predatory insects occurring on citrus trees. The larva resembles very much that of the preceding species, except the distinctions noted, and the fact that it is considerably larger. The eggs are the familiar stalked ones that may be seen extending out from the twigs or surface of the leaves. This is a provision to prevent those larvæ first hatching from devouring the eggs not yet hatched, since they are strongly cannibalistic. This precaution is not followed, how-

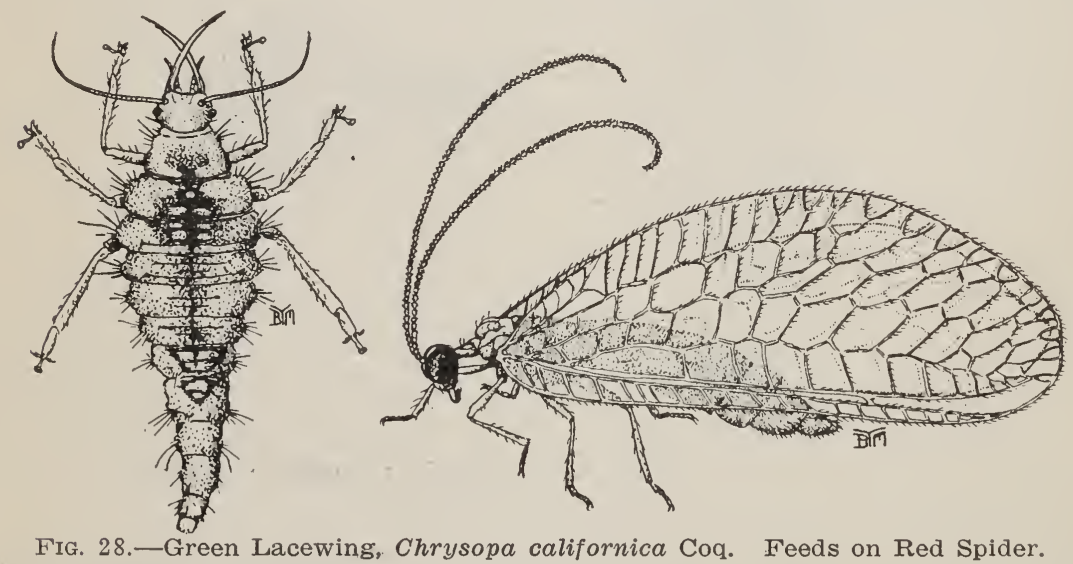

ever, in the case of the brown lacewing. The feeding habits of both of these species are much the same, and consequently need not be repeated.

The cocoon is formed on the leaf and consists of a very compact layer of closely woven silk with a more or less irregular loose covering on the cutside to hold it in place. It is oval in shape with the long axis extending vertically from the leaf. When ready to emerge the adult cuts a very even line almost around the upper third, leaving just enough to serve as a hinge for the cap that is pushed back as it emerges.

The adult is larger than the brown lacewing, measuring about three fifths of an inch to the tips of the wings. It is distinctly green in color with delicate iridescent wings. Its larger size, absence of the clothing 
of hairs, and the cylindrical, rather than beaded joints of the antennæ, will at once distinguish the adult of the green from that of the brown lacewing.

\section{Other Enemies.}

Aside from those enemies mentioned, there are some of the native Coccinellids that feed to some extent on red spiders. Probably the commonest one seen during the last couple of years has been Olla abdominalis. There are also two or three species of Syrphus fly larva that eat red spiders. Among the mites there have been noted four or five predatory ones. One of these, Fig. 15, was taken very generally over the citrus section but always in scattering numbers.

\section{THE CONTROL OF SPIDERS AND MITES ON CITRUS TREES.}

Red spiders and mites of citrus trees are not difficult to control. Neither is the expense large as compared with the control of other pests of citrus trees. For these reasons, therefore, there is little excuse for allowing such pests to do injury. By the statement that they are not difficult to control is meant that they are susceptible to various sorts of sprays, some of which may be applied dry. But they do require separate treatment where the scale insects are handled by fumigation, for fumigation has practically no effect upon them. Where spiders and mites alone are to be combated the essential ingredient in the application should be sulphur. Sulphur has the advantage over most other materials in that it remains effective for some time after the application is made. It is also cheap and not hurtful to the tree or fruit. Where spraying is still practiced for the control of scale insects, then the oil emulsions may be used for they will control the spiders at the same time.

\section{FUMIGATION NOT EFFECTIVE.}

It has been the universal experience in actual practice, as well as a problem of easy determination experimentally, that the ordinary dosage of hydrocyanic acid gas used in the fumigation of citrus trees has little effect on spiders and mites. Just why they are resistant to the gas can not be clearly explained, but it must be on account of the gas not being able to enter the spiracles in any quantity. It is scarcely possible that they could resist any amount of such gas if it actually entered the body tissues. But there are certain insects that are almost resistant to arsenical poisons though the poison may actually occur in their stomachs. So it is not inconceivable that the spiders are actually resistant to certain amounts of gas as used on citrus trees, even though such gas really enters their bodies, but it seems more likely that less actually enters through their breathing pores than is the case with most insects.

The breathing or respiratory system is very different in spiders and 
mites than it is in insects. The silver mite, for instance, is said to have no tracheal system and no openings for purposes of respiration in the body surface. Such mites secure oxygen through the general body wall by process of osmosis. In the case of the citrus red spider and the sixspotted mite the spiracles occur on either side of the rostrum. There are thus but two while most insects have several. This difference in the respiratory system between Acarina and Insects, however, does not explain all the difference in resistance to the gas, for the mealy bug, which is itself an insect, is about as resistant as spiders and mites. But in the case of the mealy bug it may be again a question of the gas not actually getting through the spiracles.

That the citrus red spider is not wholly immune to hydrocyanic acid gas is shown in the table below. The fumigation recorded was done in an airtight box of 25 cubic feet capacity. Taking the dosage in field work as one ounce to 100 cubic feet of space, the corresponding amount of potassium cyanide to use in the box would be one fourth of this, or 7.5 grams. It will be noted that the full dosage continued for one hour failed to kill but a small per cent of the eggs of the spider. The adults were all killed with this same dosage, and even down to one half hour exposure. But it should be kept in mind that on account of no leakage this dosage is really greatly in excess of that used in actual fumigation work. With the same dosage in the same box we have killed all stages of the red, black and purple scales, and even the mealy bug in 15 minutes exposure. In fumigation work, therefore, where the maximum dosage is used a few of the spiders may be killed, but only a few at best and none whatever of the eggs.

Fumigation for Red Spiders.

Capacity of fumigatorium, 25 cubic feet.

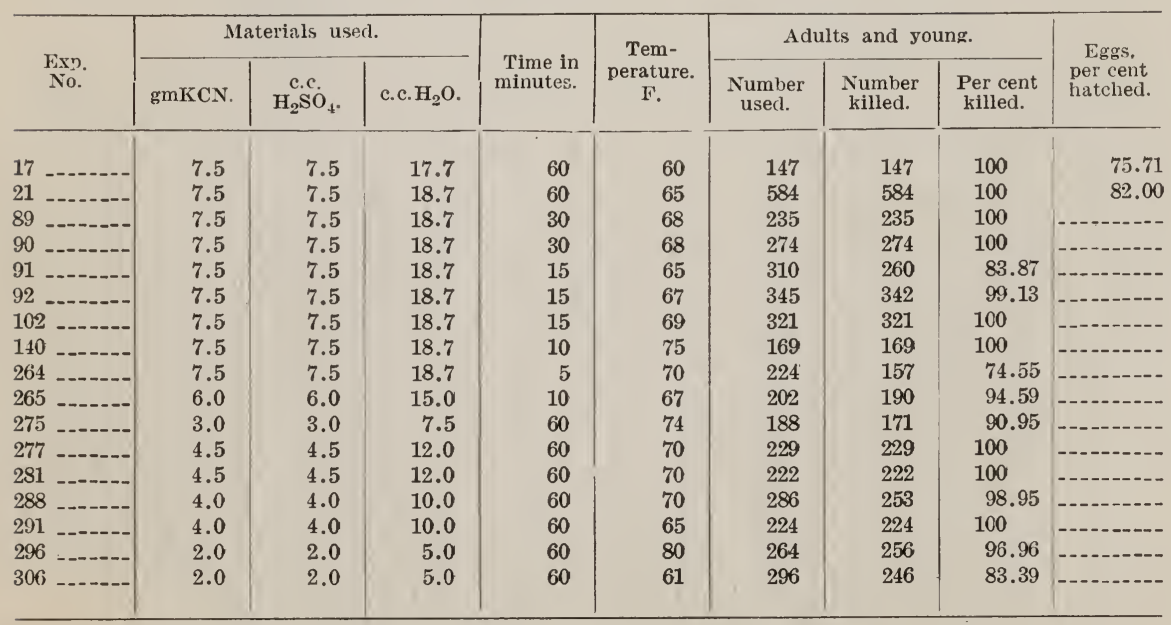




\section{LIME SULPHUR SPRAY.}

The spray that has been found to be most generally satisfactory is the ordinary commercial lime sulphur spray, properly diluted. There is no objection to the grower making his own lime sulphur concentrate if he is prepared to do so, but all things considered, the commercial article costs but little more and is more satisfactory. Most of the lime sulphur sold in the State is manufactured in the State by two different firms, and sold under the trade names of Ortho and Rex lime sulphur. These are of equal efficiency when diluted in proportion to their density or sulphur content and are simply concentrated lime sulphur solutions. Where the trade name alone is used it does not indicate that it is some special spray

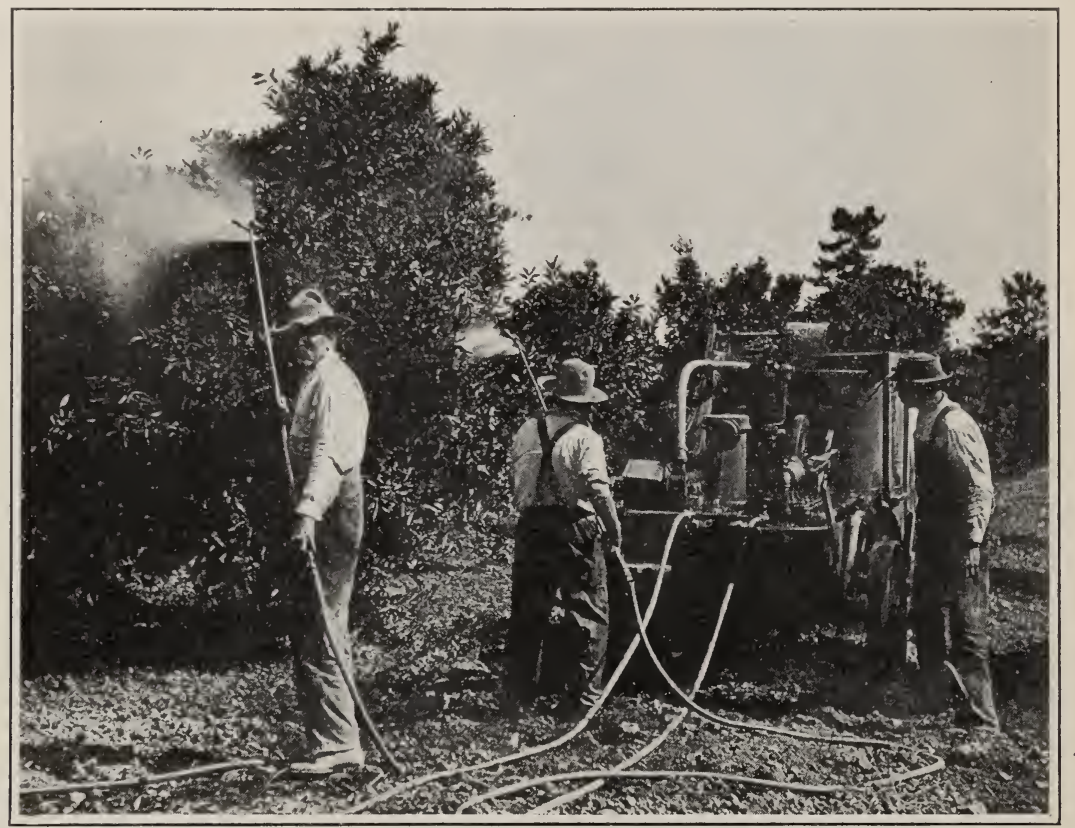

FIG. 29.--Spraying large orange trees with lime sulphur for Red Spiders.

of unknown composition but it is simply lime sulphur spray ready for use with the addition of water.

Dilutions.-During the past year or two the commercial lime sulphur has been used at dilutions of 1 to 35 and 1 to 50 . So far as we have been able to see the 1 to 50 dilution is as satisfactory as the 1 to 35 dilution. If the 1 to 50 dilution kills the spiders that is all that is necessary and there is a considerable saving in the cost. The question of burning also comes in, and during warm dry weather a considerable amount of this may occur with the 1 to 35 strength. The injury from lime sulphur is evident as brown spots on the tips or margins of the 
leaves. The spray has collected here and by the evaporation of the water it becomes much more concentrated and causes such local burning.

The dilution of one gallon of the concentrate to fifty gallons of water is intended for the $36^{\circ}$ material. That is, the product in the barrel as it comes from the manufacturer should read $36^{\circ}$ on the Baumé scale. If it is not so concentrated as this then the dilution should not be so great. Sometimes the grower dilutes according to the specific gravity spindle and the reading on this to correspond to the 1 to 50 dilution should be 1.0065 or, if the Baumé scale is used it should indicate about $1^{\circ}$.

Cost.-Where the grower hires the work done the total cost, including the materials and the application, varies from $1 \frac{1}{2}$ to $2 \frac{1}{2}$ cents a gallon as it is applied to the tree. The usual charge is $1 \frac{1}{2}$ cents where the dilution is 1 to 50 and 2 cents where the dilution is 1 to 35 . In some cases, however, $2 \frac{1}{2}$ cents is charged for the latter dilution.

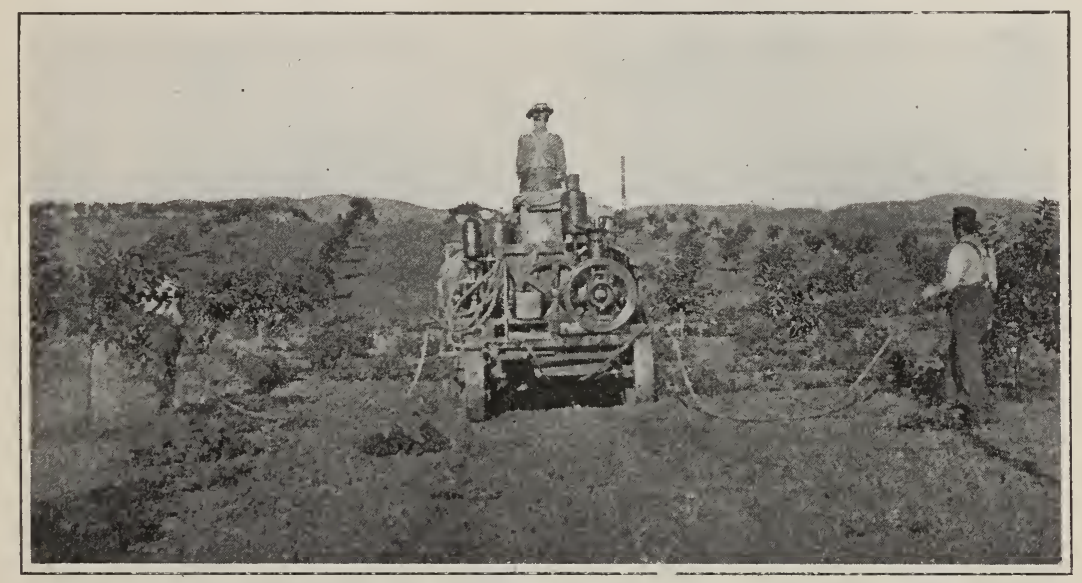

FIG. 30.-Spraying young orange trees for Red Spiders.

What the Spray Does.-The lime sulphur spray kills the spiders largely by contact. It is, therefore, important that the spray be thoroughly applied in order to reach all of the spiders. Fortunately the spiders are found mostly on the outer parts of the tree, and the usual difficulty of getting to the interior of the citrus tree with the spray is not important in this case. From our experiments and observations the lime sulphur spray does not kill all of the eggs of the spider, even though these be hit with the spray. It does, however, kill a large proportion of them. But the lime sulphur spray is not dependent on its efficiency entirely through contact. Its effect is more or less lasting, and consequently the young which may hatch from those eggs not killed will succumb usually soon after. Evidence of the spray may be seen several weeks after the application is made. In some cases, as with the 
spiders on hops and almonds in the northern part of the State, a flour paste is added to increase adhesiveness. But the addition of anything extra to the straight lime sulphur spray seems to be superfluous in the case of the citrus spiders.

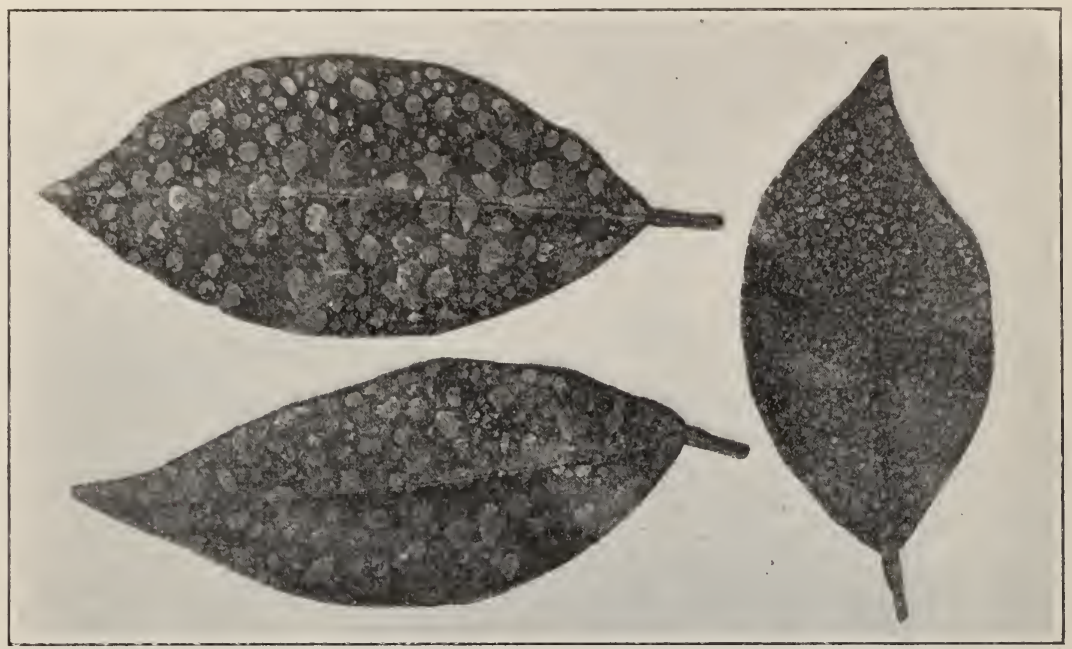

FIG. 31.-Orange leaves sprayed with lime sulphur.

DRY SULPHUR.

The earliest successful treatment for spiders or mites was sulphur applied dry or simply dusted over the plants. This still remains one of the most satisfactory remedies. But satisfactory results are more dependent upon the weather than is the ease with the spray. By proper weather conditions is meant nights with more or less moisture, and days of bright sunshine, with a temperature high enough to properly act upon the sulphur. This temperature is roughly about $75^{\circ} \mathrm{F}$. or above in the shade. Such weather conditions generally prevail in the southern California citrus belt during the spring when the spiders are most numerous.

How the Sulphur Acts. - The exact manner in which dry sulphur acts upon the spiders is still obscure. That is, it is not known whether the fumes given off are sulphurous acid gas, hydrogen sulfid, or simply the vapors of sulphur. But whatever be the nature of the actual killing substance, from a practical standpoint the range through which this killing material acts is most important. This range we have determined by experiment to be exceedingly short. A thin thread of tanglefoot was made to enclose an area containing spiders in all stages on the fruit of the lemon. Another area immediately adjoining, separated only by the thread of tanglefoot, also enclosed spiders. In the first area sulphur was thoroughly dusted while no sulphur was applied to the other area. After a day or two all the spiders were killed in the sulphured area 
while those in the other cell were unharmed. Here, then, the thickness of the strip of tanglefoot, which was no greater than No. 10 thread, was sufficient to prevent the sulphur from acting on the spiders. This was repeated several times with the same result.

How Applied.-The practical lesson to be heeded from the above experiment is that the sulphur must be thoroughly and evenly applied. There are many growers who still believe that throwing quantities of sulphur on the ground or putting handfuls in the crotches of the tree is sufficient to check the spiders. If the spiders disappear under such con-

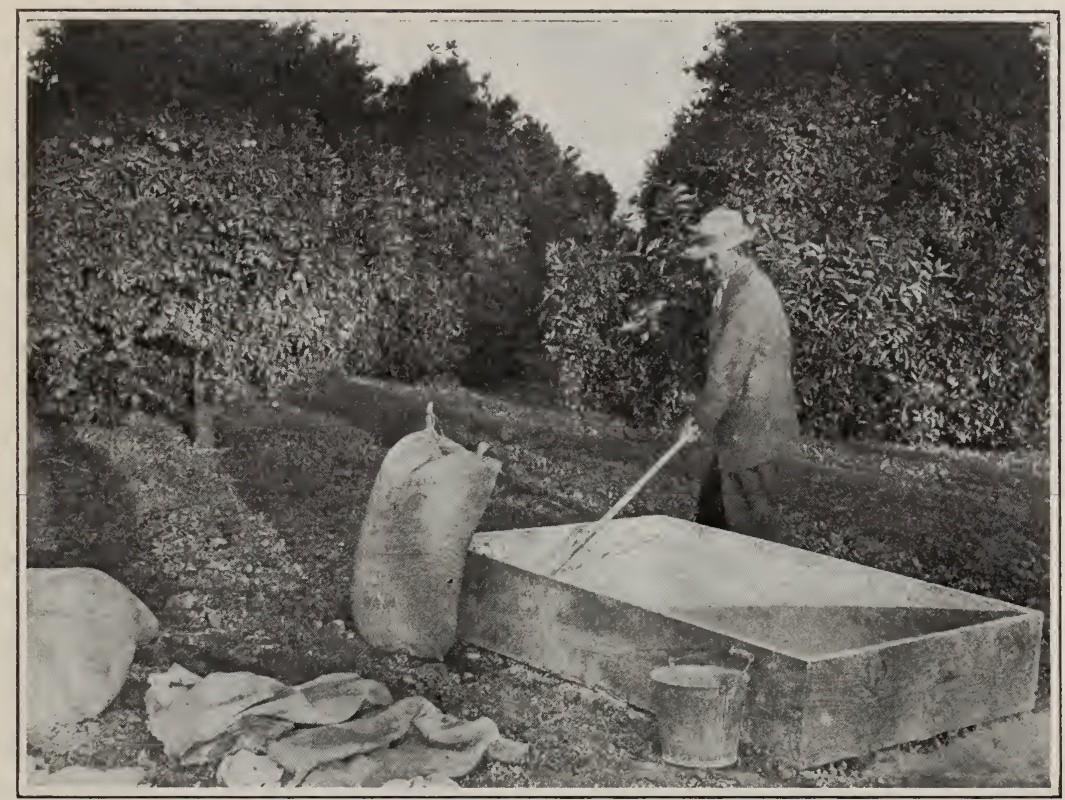

Fig. 32.-Mixing the sulphur and the hydrated lime.

ditions and by coincidence they often do, and thus the method gains credence, it is apart from any influence the sulphur may have.

If a spray is to be applied a successful grower will first secure an outfit that will properly apply the material. If dry sulphur is to be applied, many still adhere to the old-fashioned, wasteful and inefficient method of applying it by hand. Applications made in such a manner should not be expected to give satisfactory results. For large trees it is necessary to have a dust blower made for the purpose with a gasoline engine for the power. Such a machine is shown in Figs. 33 and 34 . For small trees a hand rotary bellows as shown in Fig. 35 is very satisfactory, or in the grape sections the Vermorel machine may be used.

When the Application Should be Made.-The season for applying sulphur or the sulphur spray is when the spiders first become numerous and the tree begins to show indications of injury. This is usually in the 


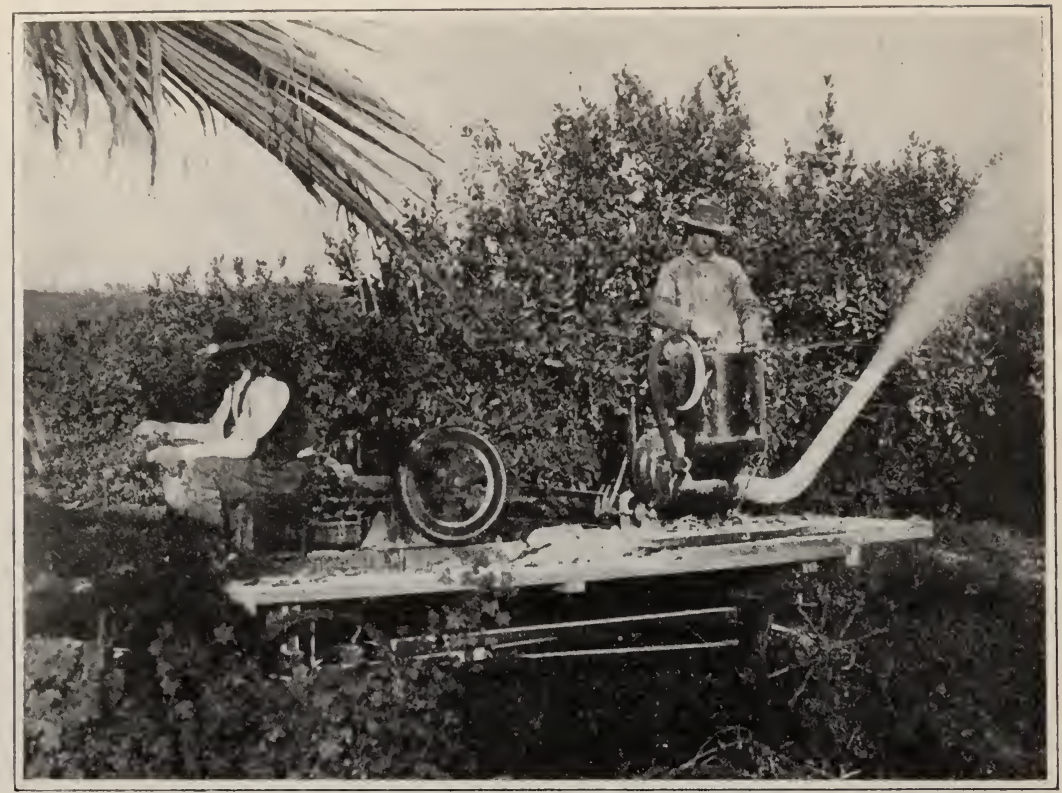

FIG. 33.-Side view of power dusting machine for applying dry sulphur and hydrated lime.

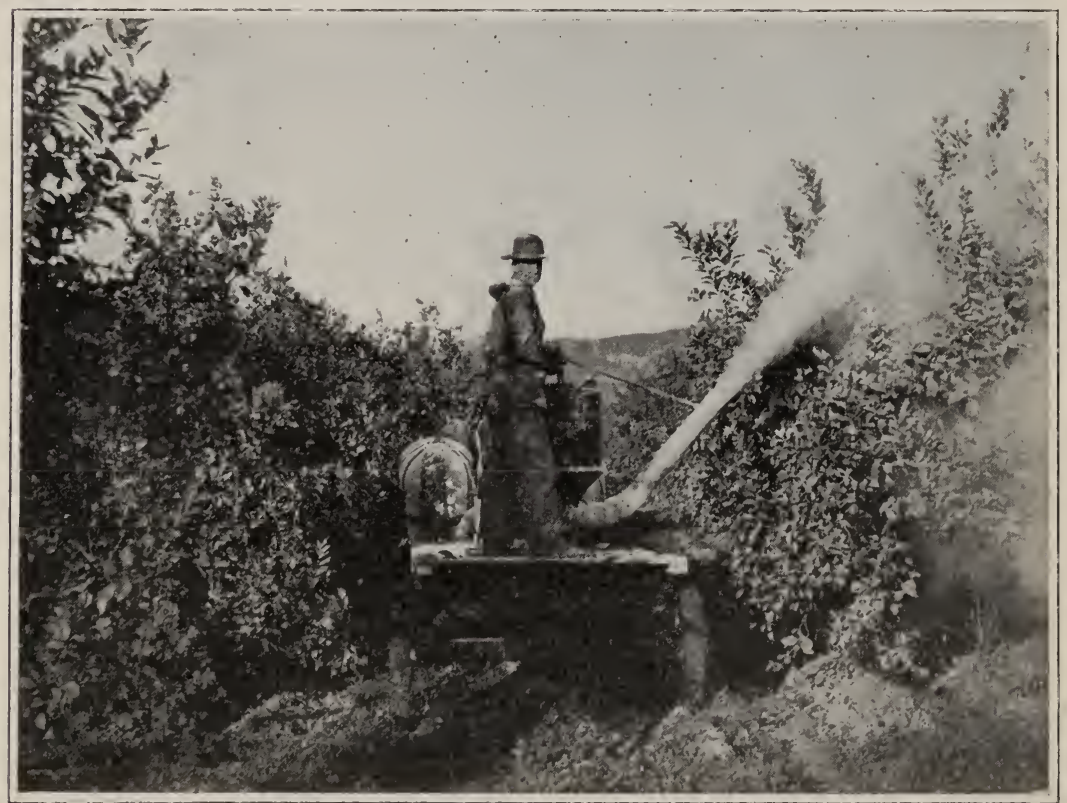

FIG. 34.-Applying dry sulphur and hydrated lime for Red Spiders. 
spring or early summer, but sometimes treatment is required at other seasons, as the fall or winter. As stated in the introduction, it is not good economy to apply treatment unless the spiders are abundant enough to warrant expenditure of the money required, which should be a saving over the injury that would be done by the spiders. On this basis some groves will require treatment while others immediately adjoining may not.

As to the time during the twenty-four hours, the application should be made very early in the morning or during the whole of the night. Experience in the Whittier section during the past year, where the work

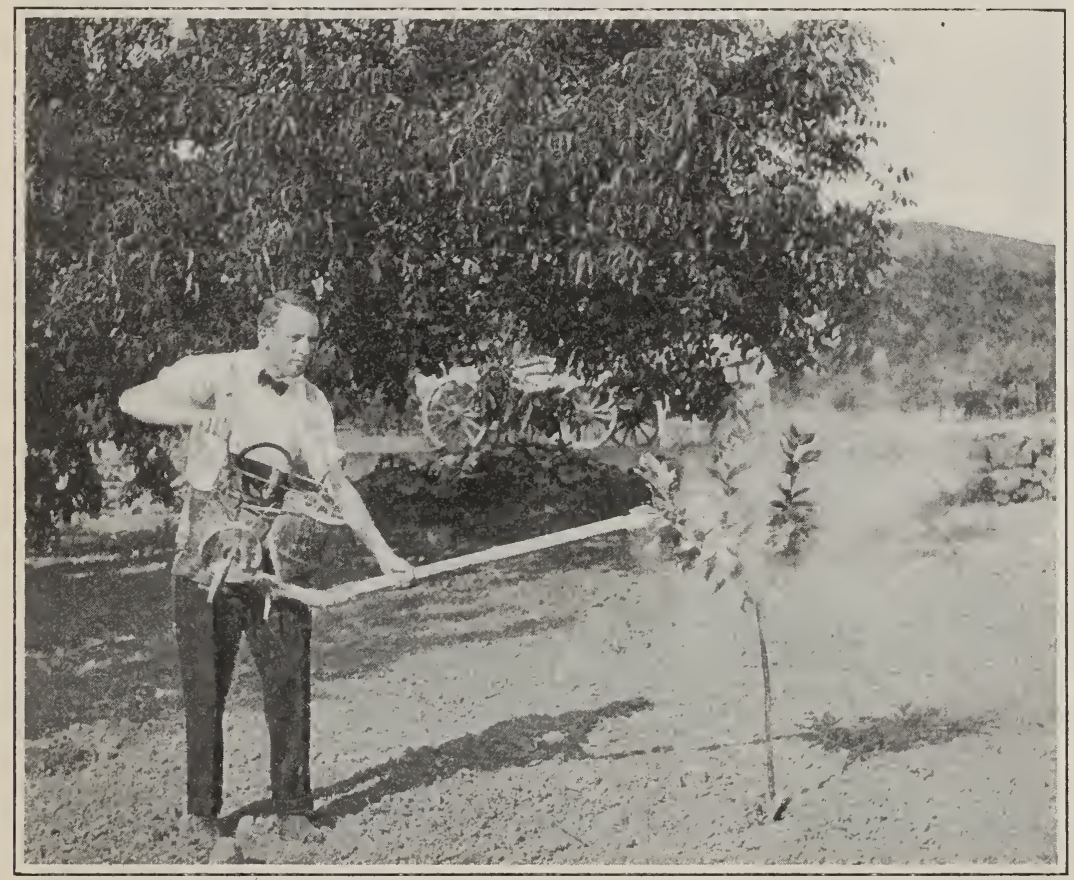

FIG. 35.-Applying dry sulphur to small citrus trees by means of a hand dusting machine.

has been done at night, indicates strongly the advantage of this time over that of the day. First, there is no wind, or at least much less than during the day; second, the moisture is sufficient to insure the sulphur adhering to the foliage. Evidence of sulphur has been noted even months after the application was made; third, aside from the moisture on the tree itself, the humidity of the atmosphere keeps the sulphur in a more definite cloud about the tree, and thus insures more settling on the tree, and, fourth, application made at night is much more satisfactory to the men. They can better avoid the cloud of sulphur, and the combination of the sulphur and the bright hot sun, which is so disagreeable, is avoided. 
Materials.-Sulphur is no longer applied alone, under the best practice. While it is still the essential ingredient, it has been found that the addition of an adhesive material adds greatly to its efficiency. This material is hydrated lime. Hydrated lime not only serves to cement the sulphur to the foliage, but also acts as a carrier and a dilutent. Hydrated lime, which is a fine, dry powder, is formed by the addition of water in the right proportion to quicklime. It is thus still caustic but not so caustic as quicklime, so that, as to properties, it may be said to occupy a position between air slaked and quick lime. Hydrated lime can be obtained in the market at a small cost. Or it may be made at home by adding 32 pounds of water to 100 pounds of the quicklime, the 32 pounds of water being taken up during the process of hydration. The precaution to be observed in its making is not to add too much water. If too much is used, more quicklime may be added.

As to sulphur, the important requisite is fineness. The same weight of sulphur will go further, can be better applied, and adheres to the tree better if it is in a finely divided condition. A finely divided sublimed or powdered sulphur is, therefore, to be preferred. The proportion of sulphur to hydrated lime varies in actual use, but the usual proportion is three parts sulphur to one of the lime. A box five or six feet square and a foot deep, as shown in Fig. 32, may be used for the mixing. Three sacks of sulphur to one of hydrated lime are put in this box and the mixing done by means of a large hoe. It is then ready to be placed in the hopper of the dust machine and applied to the tree.

Dry Sulphuring and the Fruit Pickers.-Where the harvesting of the fruit occurs a few days after the dry sulphur has been applied there is much complaint from the pickers about the disagreeableness of working in the sulphur. The schedule of sulphuring should, therefore, be arranged to follow the picking, in the case of lemons, as soon as possible, in order for sufficient time to elapse before the next picking. The sulphuring should also consider the time of harvesting the Valencia orange, since picking may occur at a time when the spiders are numerous. Sulphuring very rarely interferes with the harvesting of the Navel orange. The effects of the dry sulphur are noticeable to the pickers sometimes for two or three weeks afterward, but it should not warrant serious complaint at this time or a change in practice.

\section{THE DRY VERSUS THE LIQUID SPRAY.}

The liquid application of sprays is more generally practiced and more universally satisfactory than the dry or dust applications, with a few exceptions. Dry sulphur is more effective than the liquid for the control of the Oidium of the vine. A spray will kill only the fungus that is struck by the spray, and it is almost impossible to reach every par- 
ticle of the vine. The dust on the other hand is blown into the vine as a cloud and the whole atmosphere is charged with sulphur and all parts of the plant come in contact with it. The same thing is largely true of the red spider on citrus. The spray, however, appears to kill more than is actually hit, and the deposit of sulphur formed on the leaf continues effective for some time. But the amount of sulphur is less, and oftentimes less evenly distributed, than is the case with the dry application. The dry sulphur does not kill so quickly and two or three days to a week are necessary, depending on the weather conditions. But it will continue to act in some cases for two or three weeks afterward. The fact that in the Whittier section this year pickers have complained of the sulphur three weeks after it was applied is evidence that it is still there and active.

The dry sulphur is more easily and quickly applied but it is more disagreeable to apply. This effect also lasts more or less in the cultivation and other work in the grove, including the picking, as already explained. Some prefer to spray because they already have a spraying outfit, and it obviates the necessity of purchasing additional equipment. If the grower is to buy an outfit then the dust blower will cost less. Others spray because the lime sulphur is supposed to be efficient for the control of other troubles, as fungous diseases. But there is no evidence to show that the dry application may not also be effective against such troubles. Some prefer to spray because they are interested or have been made to become interested in the spray material. If the weather conditions are not satisfactory poor results may be expected from the dry application, while with the same weather conditions the spray will give satisfactory results. This is dependent, however, on how thoroughly the spraying is done. For, with cold weather, the spray will kill all of the spiders it hits, but it will not kill all of the eggs, and the young hatching from these will not be killed by the deposit remaining from the spray.

The question of whether the wet or the dry spray is the more desirable is, therefore, a question largely of cost. There is no doubt that an application of dry sulphur made during the spring or early summer when the spiders are usually most abundant will control them. The lime sulphur spray will also control them, and the spray has some advantages over the dry or dust method. The cost of the spray is from $1 \frac{1}{2}$ to $2 \frac{1}{2}$ cents a gallon as applied to the tree. The number of gallons required varies according to the size of the trees, but the average will be from eight to ten gallons per tree. On this basis the cost for spraying will be from 12 to 25 cents with an average of 15 to 18 cents. As compared with this. 
the dry sulphur will cost from 7 to 9 . cents a tree. This cost is calculated, from an average grove, as follows:

$\begin{array}{lr}\text { Cost of machine, labor and teams } 5 \frac{1}{2} \text { days, at } \$ 15.00 & \$ \$ .50 \\ 3520 \text { pounds sulphur at } .028 & \\ 1100 \text { pounds hydrated lime, at } .01 .80 \\ \text { Total cost }\end{array}$

The expense of applying the liquid spray will be approximately twice that of the dry or dust spray. The above figures represent the cost where the work and machine are hired done. The cost would be much less where the grower has his own outfit.

\section{DISTILLATE OR KEROSENE EMULSION.}

It often happens that the black or other scales may be desired to be controlled along with the spiders. Dry sulphur or the sulphur spray is of no use whatever against these. In such cases the distillate or kerosene (water-white oil) emulsion is most effective. Indeed the distillate emulsion has given good results, with two or three applications, with such a resistant insect as the mealy bug. Spraying is not expected to replace fumigation, but fumigation has no effect on the spiders and little effect on the mealy bug unless excessive dosages are used, or two or three applications made. Two or three applications of a spray seem to be the most desirable method, at the present time, of handling the mealy bug. If spiders occur where this insect is present, therefore, a spray that will control both pests at the same time is the most practicable.

It may happen, too, that trees, particularly small trees, infested with the black scale, or even the red scale, and the red spider, may be given one treatment for both pests. Where fumigation fails to control such a pest as the mealy bug, even though the trees and fruit be severely burned, then it is just as well to use a spray.

The injury to the trees caused by the old distillate spray is now largely avoided by the higher gravity oil, and making a good stable emulsion by the addition of soap. A certain per cent of oil in a mechanical mixture may injure the tree, but the same per cent of oil made into a stable emulsion has no injurious effect upon the tree.

The results from spraying are dependent entirely on the men behind the nozzles, if the spray material used is known to kill such as are hit. The citrus tree presents unusual difficulties, on account of its dense foliage, for covering all of its surface. A very small part of the tree can be covered from one position of the nozzle. It is thus necessary to strike the tree from every possible angle with a pressure of about 200 pounds. 
The formula for the distillate emulsion is as follows:

Distillate $32^{\circ}$ to $34^{\circ}$ Beaumé 4 gallons

Whale oil soap 10 pounds

Water 200 gallons

Put 15 or 20 gallons of hot water in the spray tank and add the soap with the agitator going. When the soap is thoroughly dissolved add the oil slowly, the agitator going at full speed in the mean time. After the oil is added and thoroughly agitated dilute to 200 gallons with cold water..

\section{Other Sprays.}

During the course of the investigation of red spiders several other sprays have been tried, both home made and commercial compounds but it is unnecessary to discuss any more than those already given.

\section{SUMMARY.}

Red spiders and mites do considerable injury to citrus trees in southern California each year. Their numbers vary greatly even in adjoining groves and treatment is unnecessary unless they are abundant and doing damage.

The citrus red spider is the most destructive of all the species and is the one most widely distributed.

The next most important species is the six-spotted mite, which makes conspicuous light-colored areas on the leaves.

Red spiders and mites live and breed entirely on the trees and are only incidentally found on the ground.

About 30 eggs are laid by each female and from eight to twelve days are necessary to bring them to maturity.

There are thus several generations in a year, varying from 12 to 15 .

They are most abundant usually during May and June, but sometimes become numerous at other seasons.

Aside from the two or three of the most injurious species we have recorded several others in these studies, making a total of 14 .

The natural enemies attacking spiders and mites are varied and numerous. The biology of many of these is given for the first time.

The most effective control measures are the application of dry sulphur and hydrated lime, or the commercial lime sulphur spray. 
REPORTS.

1896. Report of the Viticultural Work during the seasons 1887-93, with data regarding the Vintages of 1894-95.

1897. Resistent Vines, their Selection, Adaptation, and Grafting. Appendix to Viticultural Report for 1896.

1902. Report of the Agricultural Experiment Station for 1898-1901.

1903. Report of the Agricultural Experiment Station for 1901-03.

1904. Twenty-second Report of the Agricultural Experiment Station for 1903-04.

\section{BULLETINS.}

Reprint. Endurance of Drought in Soils of the Arid Regions.

No. 12s. Nature, Value, and Utilization of Alkali Lands, and Tolerance of Alkali. (Revised and Reprinted, 1905.)

133. Tolerance of Alkali by Various Cutures.

147. Culture Work of the Sub-stations.

162. Commercial Fertilizers. (Dec. 1, 1904.)

164. Poultry Feeding and Proprietary Foods.

167. Manufacture of Dry Wines in Hot Countries.

168. Observations on Some Vine Diseases in Sonoma County.

169. Tolerance of the Sugar Beet for Alkali.

170. Studies in Grasshopper Control.

171. Commercial Fertilizers. (June $30,1905$.

174. A New Wine-cooling Machine.

176. Sugar Beets in the San Joaquin Valley.

177. A New Method of Making Dry Red Wine.

178. Mosquito Control.

179. Commercial Fertilizers. (June, 1906.)

181. The Selection of Seed-Wheat.

182. Analyses of Paris Green and Lead Arsenate. Proposed Insecticide Law.

183. The California Tussock-moth.

184. Report of the Plant Pathologist to July 1,1906 .

185. Report of Progress in Cereal Investigations.

186. The Oidium of the Vine.

187. Commercial Fertilizers. (January, 1907.)

188. Lining of Ditches and Reservoirs to Prevent Seepage Losses.

189. Commercial Fertilizers. (June, 1907.)

191. California Peach Blight

192. Insects Injurious to the Vine in California.

194. Commercial Fertilizers. (Dec., 1907.)

195. The California Grape Rootworm.

197. Grape Culture in California; Improved Methods of Winemaking; Yeast from California Grapes.
No. 198. The Grape Leaf-Hopper

199. Bovine Tuberculosis.

201. Commercial Fertilizers. (June, 1908.)

202. Commercial Fertilizers. (December, 1908.)

203. Report of the Plant Pathologist to July 1, 1909

204. The Dairy Cow's Record and the Stable.

205. Commercial Fertilizers. (December, 1909.)

206. Commercial Fertilizers. (June, 1910.)

207. The Control of the Argentine Ant.

208. The Late Blight of Celery.

209. The Cream Supply.

210. Imperial Valley Settlers' Crop Manual.

211. How to Increase the Yield of Wheat in California.

212. California White Wheats.

213. The Principles of Wine-making.

214. Citrus Fruit Insects.

215. The Housefly in its Relation to Public Health.

216. A Progress Report upon Soil and Climatic Factors Influencing the Composition of Wheat.

217. Honey Plants of California.

218. California Plant Diseases.

219. Report of Live Stock Conditions in Imperial County, California.

220. Fumigation Studies No. 5 ; Dosage Tables.

221. Commercial Fertilizers. October, 1911.)

222. The Red or Orange Scale.

223. The Black Scale.

224. The Production of the Lima Bean.

225. Tolerance of Eucalyptus for Alkali.

226. The Purple Scale.

227. Grape Vinegar.

228. Pear Thrips and Peach Tree Borer.

229. Hog Cholera and Preventive Serum.

230. Enological Investigations.

231. Walnut Culture in California. Walnut Blight.

232. Commercial Fertilizers.

233. Three Years' Work of the Ferndale (Humboldt County) Cow Testing Associations. 


\section{CIRCULARS.}

No. 1. Texas Fever.

7. Remedies for Insects.

9. Asparagus Rust.

10. Reading Course in Economic Entomology.

11. Fumigation Practice.

29. Preliminary Announcement Concerning Instruction in Practical Agriculture upon the University Farm, Davis, Cal.

39. Instruction in Practical Agriculture at the University Farm.

46. Suggestions for Garden Work in California Schools.

52. Information for Students Concerning the College of Agriculture.

55. Farmers' Institute and University Extension in Agriculture.

60. Butter Scoring Contest, 1910.

61. University Farm School.
No. 62. The School Garden in the Course of Study.

63. How to Make an Observation Hive.

65. The California Insecticide Law.

66. Insecticides and Insect Control.

67. Development of Secondary School Agriculture in California.

68. The Prevention of Hog Cholera.

69. The Extermination of MorningGlory.

70. Observation of the Status of Corn Growing in California.

74. Rice.

75. A New Leakage Gauge.

76. Hot Room Callusing.

77. University Farm School.

78. Announcement of Farmers' Short Courses for 1912

79. List of Insecticide Dealers. 